\title{
Pharmacotherapy for Status Epilepticus
}

\author{
Eugen Trinka $^{1,3,4} \cdot$ Julia Höfler $^{1,3} \cdot$ Markus Leitinger $^{1,3} \cdot$ Francesco Brigo $^{2}$
}

Published online: 27 August 2015

(C) The Author(s) 2015. This article is published with open access at Springerlink.com

\begin{abstract}
Status epilepticus (SE) represents the most severe form of epilepsy. It is one of the most common neurologic emergencies, with an incidence of up to 61 per 100,000 per year and an estimated mortality of $20 \%$. Clinically, tonic-clonic convulsive SE is divided into four subsequent stages: early, established, refractory, and superrefractory. Pharmacotherapy of status epilepticus, especially of its later stages, represents an "evidence-free zone," due to a lack of high-quality, controlled trials to inform clinical decisions. This comprehensive narrative review focuses on the pharmacotherapy of SE, presented according to the four-staged approach outlined above, and providing pharmacological properties and efficacy/safety data for each antiepileptic drug according to the strength of scientific evidence from the available literature. Data sources included MEDLINE and back-tracking of references in pertinent studies. Intravenous lorazepam or
\end{abstract}

Eugen Trinka

e.trinka@salk.at

1 Department of Neurology, Christian Doppler Klinik, Paracelsus Medical University Salzburg, Ignaz Harrerstrasse 79, 5020 Salzburg, Austria

2 Department of Neurological and Movement Sciences, University of Verona, Verona, Italy

3 Centre for Cognitive Neurosciences Salzburg, Salzburg, Austria

4 University for Medical Informatics and Health Technology, UMIT, Hall in Tirol, Austria intramuscular midazolam effectively control early SE in approximately $63-73 \%$ of patients. Despite a suboptimal safety profile, intravenous phenytoin or phenobarbital are widely used treatments for established SE; alternatives include valproate, levetiracetam, and lacosamide. Anesthetics are widely used in refractory and super-refractory SE, despite the current lack of trials in this field. Data on alternative treatments in the later stages are limited. Valproate and levetiracetam represent safe and effective alternatives to phenobarbital and phenytoin for treatment of established SE persisting despite first-line treatment with benzodiazepines. To date there are no class I data to support recommendations for most antiepileptic drugs for established, refractory, and super-refractory SE. Limiting the methodologic heterogeneity across studies is required and high-class randomized, controlled trials to inform clinicians about the best treatment in established and refractory status are needed. 


\section{Key Points}

Initial treatment of early status epilepticus (SE) with intravenous lorazepam or intramuscular midazolam is able to control seizures in 63-73\%; buccal midazolam may be an alternative whenever intravenous or intramuscular application of other benzodiazepines is not possible.

In established SE, intravenous antiepileptic drugs (phenytoin/fosphenytoin, valproate, levetiracetam, phenobarbital) are most commonly used, but there is no class I evidence for choosing one over the other; valproate and levetiracetam represent safe and effective alternatives to phenobarbital and phenytoin; lacosamide is another potential alternative to phenytoin and phenobarbital, but current evidence is too sparse to give recommendations.

Refractory and super-refractory SE is treated with anesthetics (propofol, midazolam, thiopental/ pentobarbital) with lower success rates and a high morbidity and mortality. Potential drugs to be considered in super-refractory SE are ketamine, magnesium, and immunomodulatory treatments, as well other cause-directed and non-medical treatments.

Other drugs which might be useful in the treatment of SE, such as clonazepam, paraldehyde, chlormethiazole (clomethiazole), or lidocaine, have a long history, but there is no higher-class evidence to support their use other than as second or third alternatives in refractory cases.

\section{Introduction}

Status epilepticus (SE) can be regarded as the most severe and extreme form of an epileptic seizure. Tonic-clonic SE (i.e., convulsive SE, CSE) can be defined as ongoing convulsive seizure activity or repeated convulsive seizures, without regaining consciousness between seizures, for more than 5 min [1]. Non-convulsive SE (NCSE) can be defined as an "enduring epileptic condition with reduced or altered consciousness, behavioral and vegetative abnormalities, or merely subjective symptoms like auras, but without major convulsive movements for more than 30 min" [2, 3]. A Task Force of the International League Against Epilepsy (ILAE) recently defined SE as "a condition resulting either from the failure of the mechanisms responsible for seizure termination or from the initiation of mechanisms, which lead to abnormally prolonged seizures (after time point $\mathrm{t} 1$ )... which can have long-term consequences (after time point $t 2$ ), including neuronal death, neuronal injury, and alteration of neuronal networks, depending on the type and duration of seizures". [4]. The time limits for $\mathrm{t} 1$ were set at $5 \mathrm{~min}$ for generalized convulsive SE, and $10 \mathrm{~min}$ for focal SE with impaired consciousness (formerly complex-partial SE). In the new classification NCSE is divided into those patients with and without coma following two broad clinical categories: while the former are "ictally comatose", often seen as a progression of CSE, the "walking wounded" with aura continua, absence status, or focal SE with impaired consciousness have a less severe prognosis and do usually not need the full armamentarium of emergency treatment as described below.

SE is most prevalent in the population with structural brain damage. In patients with epilepsy, SE can be precipitated by drug withdrawal, intercurrent illness, or metabolic disturbance. The mortality of SE is around $20 \%$, but may be as high as $40 \%$ in the elderly with acute symptomatic SE [5-9] and many co-morbidities [10]. The annual incidence has been estimated to be approximately 18-28 cases per 100,000 per year, but may be as high as 61 per 100,000 per year, depending on the population studied [11-16]. The incidence is highest in the elderly and has a second peak in the neonatal period [17-22].

Although the first descriptions go back to Babylonian Times (Sakikku-Board, 718-614 BC) [23] and recognition of absence status was evident in the 16th century [24], detailed descriptions of the clinical picture and first pathophysiology considerations occurred in the 19th and 20th centuries. In their seminal work, Clark and Prout recognized three phases of CSE [25-27]:

(a) In patients with epilepsy, an early phase can be characterized, where frequency and severity of seizures increases in a crescendo pattern. Synonyms are premonitory status, impending status, and heraldic status. In patients without pre-existing epilepsy, the phase with a crescendo-like increase in seizure frequency and severity is missing, and SE starts abruptly. Ongoing convulsive epileptic activity for more than $5 \mathrm{~min}$ is now often called early SE.

(b) Established SE designates continuous seizure activity with convulsions or intermittent seizures without regaining consciousness between the seizures. For more than 10 and up to $30 \mathrm{~min}$, or failure of initial treatment (usually benzodiazepines) of early SE.

(c) With increasing duration, a decrease in motor activity (electromechanical dissociation) occurs while the patient remains in a coma. This phase is called 
advanced SE or refractory SE, referring to the failed treatment (usually with antiepileptic drugs, AEDs) of early and established SE. Other terms are subtle SE or stuporous SE.

(d) At the third London-Innsbruck Colloquium on Status Epilepticus [28], the fourth stage of SE, called superrefractory SE, was characterized. At this stage seizures continue despite maximal treatment with intravenous (IV) anesthetics for more than $24 \mathrm{~h}$ in an intensive care unit. These patients have ictal EEG discharges when anesthesia is lessened. This stage has also been termed malignant SE [29] (Fig. 1).

It has to be acknowledged that there is no clear definition of the stages and one might merge into the other. While Clark and Prout described the stages of SE in mostly untreated patients, clinical practice now defines the first stage with a time frame (5 min of convulsive and $10 \mathrm{~min}$ of focal non-convulsive), and the later stages by treatment response: it has now been commonly accepted to designate established SE as "benzodiazepine-resistant SE," while the term refractory SE is used, when treatment with benzodiazepines and one or more IV AEDs have failed. This also implies that the timeframes given above, which are used by most clinicians, may vary considerably with treatment. By nature this lack of clear definitions leads to a high degree of variability in the current literature.

In 2007, at the First London-Innsbruck Colloquium on Status Epilepticus, a workshop was held with the purpose of outlining the options of optimal pharmacotherapy of the various forms of SE. A consensus was reached and a treatment protocol published, which followed the conventional pattern of tonic-clonic SE established [30, see Flow chart in "Appendix"]. The European Federation of Neurological Societies and other groups have also published similar recommendations [31, 32]. Recent reviews [33, 34] covered the history of pharmacotherapy of SE outlining the enormous range of therapies that have been advocated since the 19th century.

Data on the pharmacotherapy of SE are most often observational, having a high degree of heterogeneity and high-class randomized, controlled trials are only available for the early stages of SE. Therefore we discuss the pharmacotherapy of SE in a narrative, rather than in a systematic review. In this article we will review the data following the same principles of a staged approach as outlined above.

Treatment of SE, especially of its later stages, the pharmacological management of which represents a terra incognita [28], is almost an "evidence-free zone," due to a lack of adequate numbers of high-quality, controlled trials to inform clinical decisions, especially in the later stages of the disorder. In most clinical trials performed in this area, often burdened by severe methodologic limitations including excessive clinical heterogeneity, investigators use different definitions of SE (and its stages), adopt inappropriate comparators, or use unclear methods of data presentation [35-37], so that reaching definite evidence is an extremely challenging task.

Given this serious limitation, in this narrative review we presented the most relevant studies on this topic (Table 1) taking into account the "evidence-pyramid" [38]: whenever available, data from controlled clinical trials (randomized/not randomized) were preferred over uncontrolled trials or case series, unless reporting relevant clinical results in terms of efficacy or tolerability. Similarly,
Fig. 1 Clinical course of convulsive status epilepticus (SE)

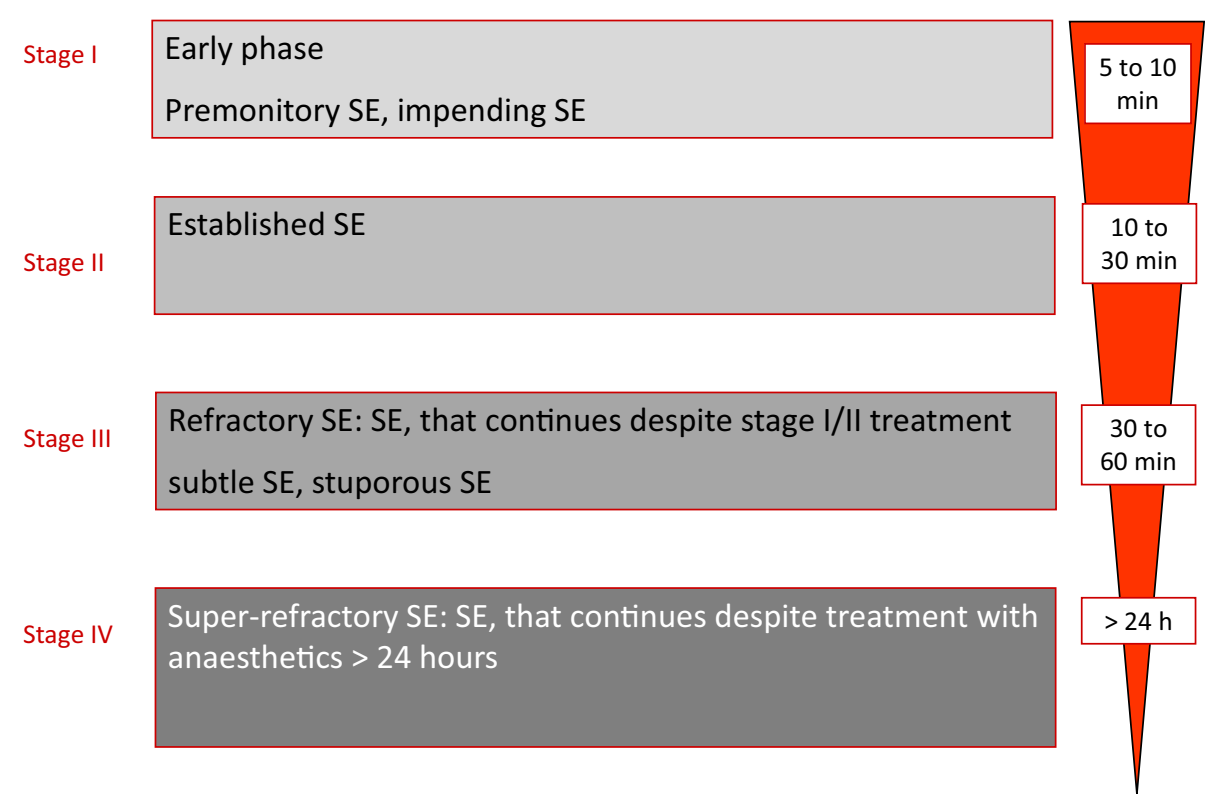




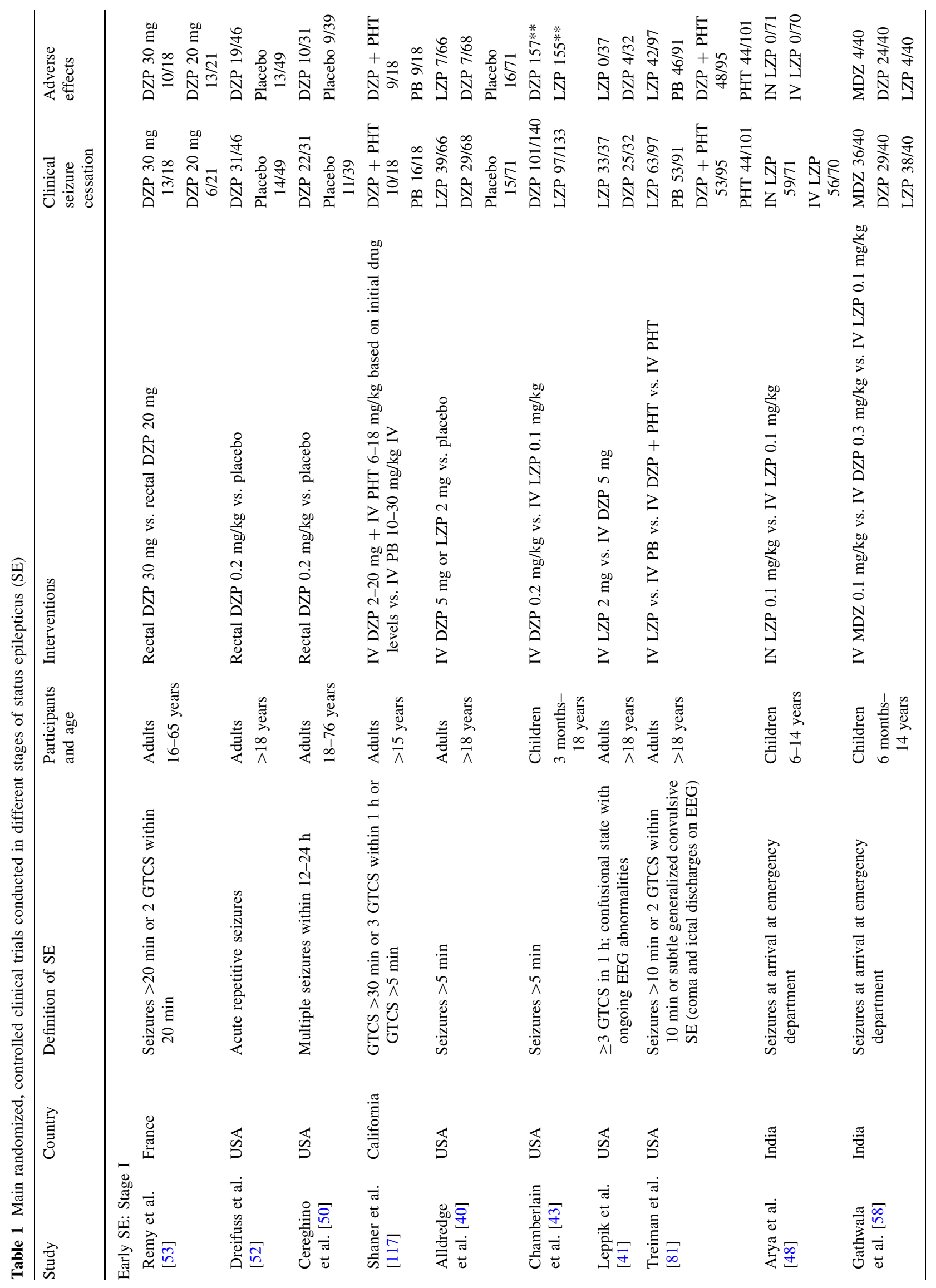




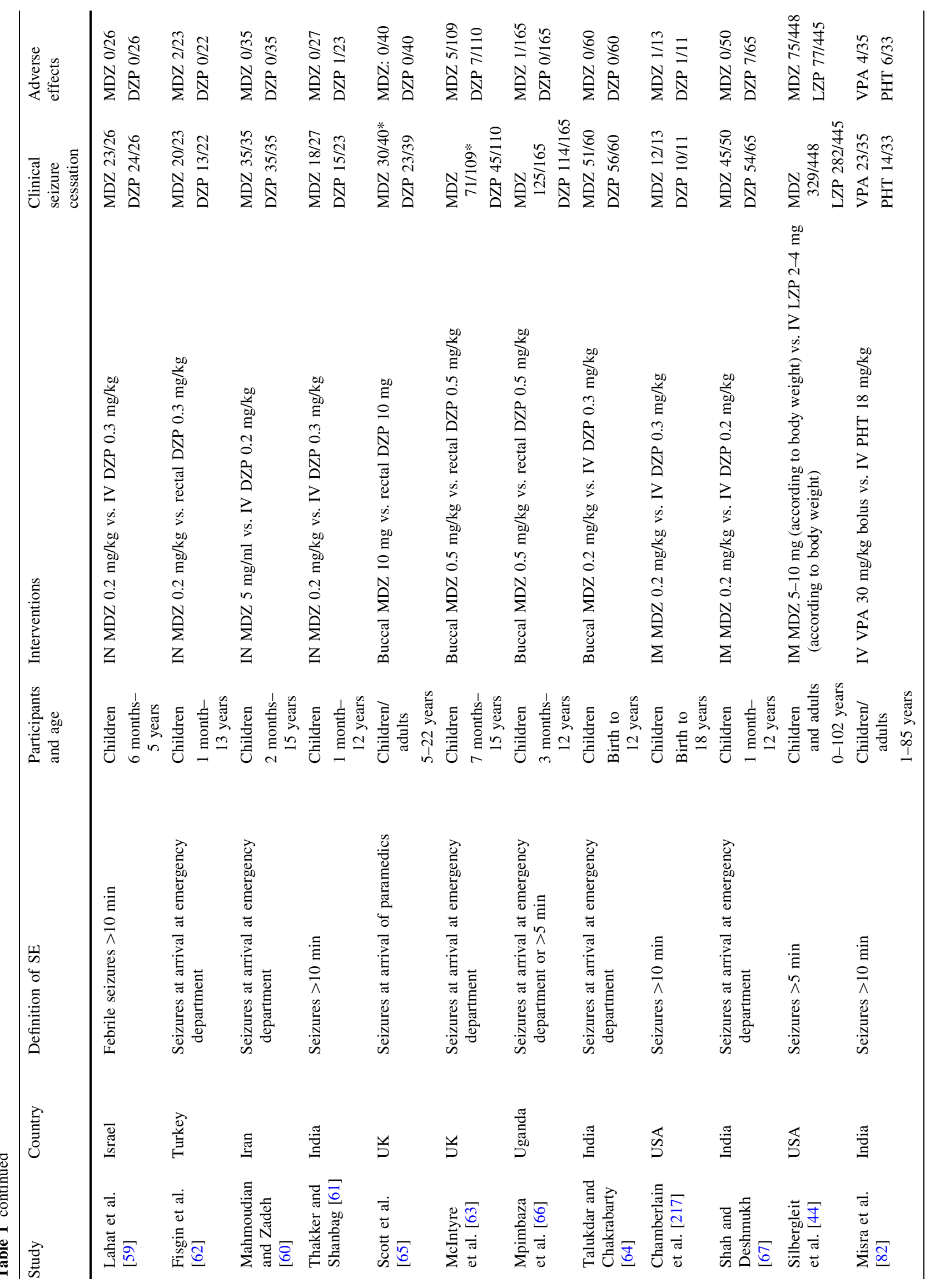




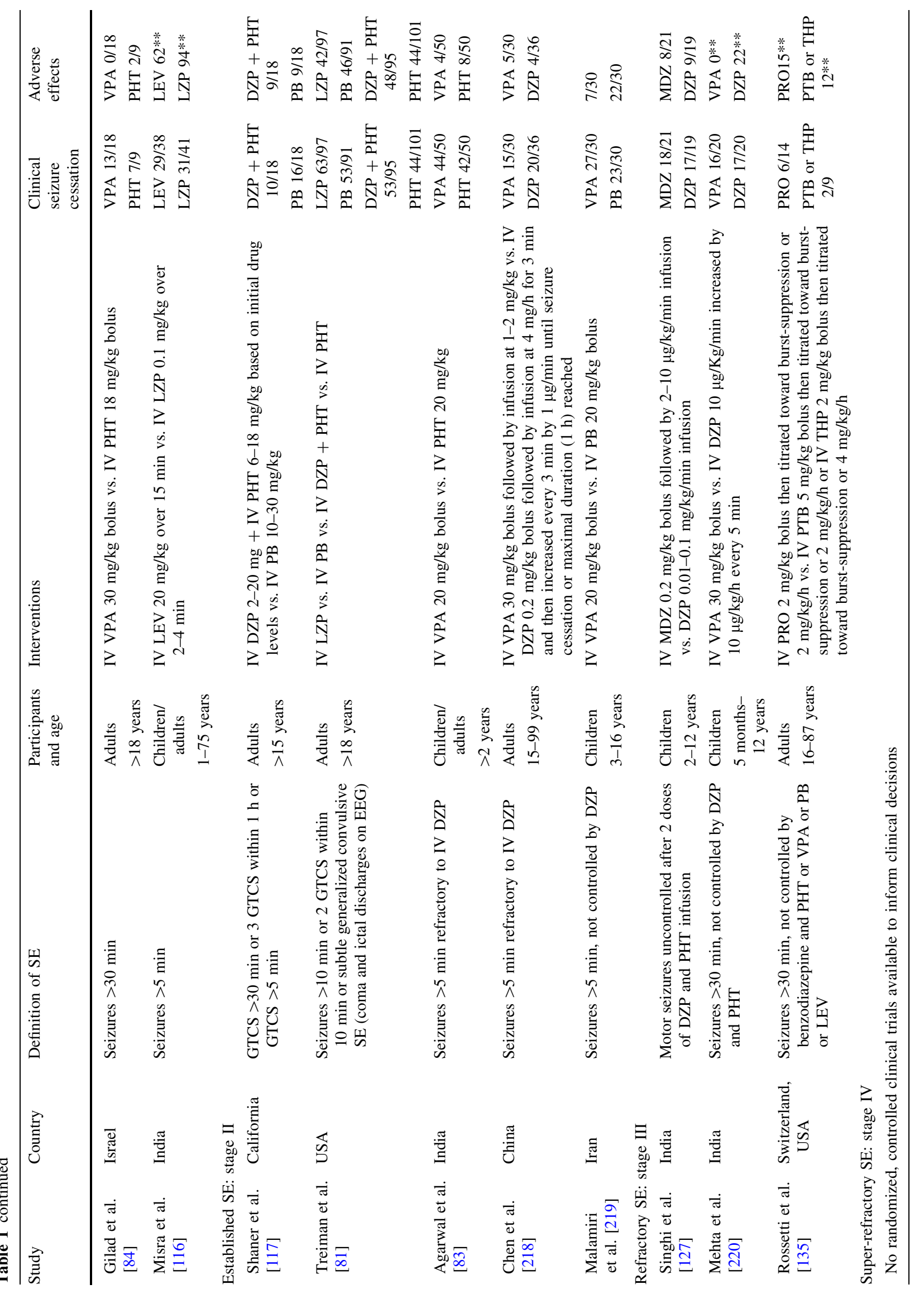


cumulative data obtained from high-quality systematic literature reviews were reported as the best available evidence on this topic.

\section{Early Status Epilepticus: Stage I}

All AEDs commonly used as first-line treatment in SE are benzodiazepines. These drugs bind to the gammaaminobutyric acid (GABA)-A receptors, increasing channel opening frequency at the receptor, with subsequent increased chloride conductance and neuronal hyperpolarization, leading to enhanced inhibitory neurotransmission and antiepileptic action [39].

\subsection{Lorazepam (Intravenous (IV) and Intranasal (IN))}

Lorazepam can be administered either intravenously or intranasally, although to date most evidence in the treatment of SE refers to its IV use. Although it has a longer initial duration of action than diazepam, lorazepam administered intravenously is usually preferred as initial treatment of early SE, because it is less lipid-soluble and consequently does not undergo the rapid redistribution into peripheral tissues seen with diazepam. This pharmacologic advantage has been clinically substantiated in randomized, controlled trials comparing IV lorazepam with placebo [40], IV diazepam [41-43], and IM midazolam [44]. In a meta-analysis, lorazepam was better than placebo for risk of non-cessation of seizures (relative risk (RR) $0.52 ; 95 \%$ confidence interval (CI) 0.38-0.71), better than diazepam for reducing risk of non-cessation of seizures (RR 0.64; $95 \%$ CI 0.45-0.90), and had a lower risk for continuation of $\mathrm{SE}$ requiring a different drug or general anesthesia (RR 0.63 ; $95 \%$ CI $0.45-0.88)$ [36, 45]. There was no statistically significant difference between lorazepam and diazepam administered intravenously in terms of respiratory failure/depression, or hypotension [36, 45].

IM midazolam was non-inferior to IV lorazepam in a landmark study in early SE [44] (see Sect. 2.4 for details). Recently an intranasal (IN) administration of lorazepam has been proposed as an alternative, non-invasive delivery route for this drug, considering the favorable pharmacokinetics with rapid absorption from the IN route leading to rapid blood concentrations required for seizure termination $[46,47]$. The favorable pharmacokinetics of IN lorazepam in relation to standard (IV) administration have been confirmed in one randomized, open-label non-inferiority trial conducted in 141 consecutive children aged 6-14 years who presented with convulsions to the emergency room, showing that IN lorazepam was not inferior to IV lorazepam in terms of clinical seizure remission within 
10 min of drug administration [48]. It has to be noted that this study included not only children in SE, but also those who had a seizure in the emergency room, which can explain the high rate of treatment success, potentially leading to a bias towards non-inferiority.

\subsection{Diazepam (IV, Rectal)}

Diazepam is a highly lipophilic benzodiazepine, which rapidly enters into the brain but subsequently is rapidly redistributed into peripheral tissues [39]. This pharmacokinetic property is responsible for its fast anticonvulsant effect in spite of its longer elimination half-life. Diazepam can be administered either intravenously or rectally, with demonstrated significantly higher efficacy over placebo in terms of controlling acute repetitive convulsive seizures in adults and children for both methods of administration [40, 49-52]. Diazepam $30 \mathrm{mg}$ intrarectal gel was found to have higher efficacy than $20 \mathrm{mg}$ in seizure cessation without any statistically significant increase in adverse effects [53].

A meta-analysis of the literature indicates that, compared with placebo, after diazepam administration there is a lower risk of requirement for ventilator support and continuation of SE requiring a different drug or general anesthesia with diazepam (304 patients included overall) [36]. In a recent double-blind, randomized, controlled, superiority trial IV diazepam was compared to IV lorazepam in pediatric SE [43]. 273 children aged 3 months to $<18$ years were randomized to either $0.2 \mathrm{mg} / \mathrm{kg}$ diazepam $(n=140)$ or $0.1 \mathrm{mg} / \mathrm{kg}$ lorazepam $(n=133)$. The rates for cessation of SE within $10 \mathrm{~min}$ and without recurrence over $30 \mathrm{~min}$ were $72.1 \%(101 / 140)$ in the diazepam group and $72.9 \%(97 / 133)$ in the lorazepam group. There were also no differences in all secondary outcomes (e.g., requirement of assisted ventilation), except that patients in the lorazepam group were more often sedated (66.9 vs. $50 \%)$.

\subsection{Clonazepam (IV)}

Clonazepam is more lipophilic than lorazepam, but less lipophilic than diazepam, making it therefore less prone to redistribution. Its long half-life of $17-55 \mathrm{hs}$ and rapid onset of action makes it an attractive agent for emergency treatment of seizures and SE. To date, there is limited evidence to support the use of IV clonazepam in the treatment of early SE. In one uncontrolled case series (17 children) with SE treated with this drug, seizure cessation was reported in all patients after administration of doses between 0.25 and $0.75 \mathrm{mg}$, with no adverse effects reported [54]. In a subsequent uncontrolled, open-label trial (24 patients), the administration of an IV bolus injection of 1-2 mg clonazepam led to complete control of $100 \%$ (7/7) petit mal, $50 \%(7 / 14)$ grand mal, and $66 \%$ of partial complex cases of SE (mean time to clinical seizure cessation after administration was $1.75 \mathrm{~min}$ ) [55]. Adverse effects consisted exclusively of transient mild to moderate drowsiness occurring in $40 \%$ of the patients. One study comparing IV clonazepam alone to clonazepam followed by levetiracetam in generalized CSE was reported to recruit in 2011, but final results have not been published yet [56].

Quite surprisingly, despite these favorable preliminary data, no further controlled trials has been conducted to evaluate efficacy and tolerability of this drug in the treatment of SE. Despite this lack of evidence, clonazepam is extensively used in France, The Netherlands, Belgium, and other European countries.

\subsection{Midazolam (IV, Intramuscular (IM), Intranasal, Buccal)}

Midazolam is a benzodiazepine with the advantage of multiple routes of administration, due to its water solubility. At physiologic $\mathrm{pH}$ the ring structure of midazolam closes and it becomes highly lipophilic, crossing the bloodbrain barrier rapidly [57].

Midazolam administered intravenously was found to be similar in terms of seizure recurrence to IV diazepam or IV lorazepam in a pediatric non-randomized, controlled trial, with no significant differences in mean duration to clinical seizure cessation [58].

A recent double-blind, randomized, non-inferiority trial compared the efficacy of IM midazolam with that of IV lorazepam for children and adults with CSE treated by paramedics before admission to hospital [44]. Midazolam was found to be at least as safe and effective as IV lorazepam: at the time of arrival in the emergency department, seizures were absent without rescue therapy in $73.4 \%$ (329/448) in the IM-midazolam group and in $63.4 \%$ (282/ $445)$ in the IV-lorazepam group. The two treatment groups were similar with regard to the need for endotracheal intubation (14.1\% of subjects with midazolam and $14.4 \%$ with lorazepam) and recurrence of seizures $(11.4 \%$ and $10.6 \%$, respectively). Among subjects whose seizures ceased before arrival in the emergency department, the median times to active treatment were significantly lower in the midazolam group, although the onset of action (i.e., seizure cessation) occurred sooner after IV lorazepam administration, and adverse-event rates were similar in the two groups. Overall, these findings indicate that IM midazolam is a practical, safe, and effective alternative to IV lorazepam for the treatment of prolonged convulsive seizures in prehospital settings.

In general, IN and buccal routes of administration are more convenient than IV administration for the treatment of SE, because these formulations deliver the medication 
non-invasively and more rapidly than by the IV route, and may be used also by paramedics. In three randomized, controlled trials comparing IN midazolam with IV diazepam, IN midazolam was equally effective as IV diazepam, with a lower mean time to control of seizures in the midazolam group than in the diazepam group, and no significant side effects observed in either group [59-61]. In addition, IN midazolam was found to be more effective than rectal diazepam in children with prolonged convulsive seizures, without serious complications [62].

In a prospective randomized trial, buccal midazolam was found to be more effective than rectal diazepam in children with convulsive febrile seizures [63]. No statistically significant differences in terms of efficacy were found in other studies comparing buccal midazolam with IV diazepam [64] or rectal diazepam [65, 66]. These findings support treatment protocols recommending its use as firstline treatment of acute tonic-clonic seizures in childhood including CSE where IV access is difficult or not available [31]. Time to obtain IV access may be relevant, and may explain a shorter time for controlling the convulsive episodes in patients receiving buccal midazolam compared with patients treated with IV [64] or rectal [65] diazepam. Similarly, in a study in children comparing IM midazolam and IV diazepam, mean interval to cessation of convulsions with IM midazolam was found to be significantly lower than in the diazepam group without prior IV access [67].

\section{Established Status Epilepticus: Stage II}

\subsection{Phenytoin/Fosphenytoin (IV)}

Phenytoin has a pKa of 8.3 and is highly lipid soluble but insoluble in water. To keep phenytoin in solution it has to be prepared in a highly alkaline solvent with $\mathrm{pH}$ values of around 12 [68]. It has been used extensively over the past 50 years in the treatment of SE [68], but it took almost 20 years to recognize the appropriate doses of phenytoin to be effective in SE [69]. Due to its slow rate of infusion (maximum $50 \mathrm{mg} / \mathrm{min}$ ) and its delayed onset of action, it should not be used in early SE [30-32, 70] The recommended dose is $18-20 \mathrm{mg} / \mathrm{kg}$ for adults and $15 \mathrm{mg} / \mathrm{kg}$ in the elderly ( $>65$ years). Though phenytoin is not sedative, hypotension (28-50\%) and cardiac arrhythmias (2\%) may complicate the treatment $[71,72]$. Patients over the age of 50 years and with pre-existing cardiac disease are at special risk for cardiovascular complications of phenytoin [71]. Phenytoin needs polypropylene glycol in an alkaline solution to prevent precipitation of the substance, which may result in local irritation, thrombophlebitis, compartment syndrome, and 'purple glove syndrome,' as well as tissue necrosis with extravasation [73-76].
Despite its long-standing use in SE there are only nine studies including four randomized, controlled studies in adults and children with various forms and stages of SE [69, 77-84]. In a randomized, controlled, double-blind study for initial treatment of tonic clonic status, IV phenytoin alone was significantly less effective (defined as cessation of all clinical and electrographic seizure activity within $20 \mathrm{~min}$ after the start of infusion and absence of seizure relapse $60 \mathrm{~min}$ after treatment onset) than lorazepam (43.6 vs. $64.9 \%, p=0.002)$. In three other studies, two in early SE [82, 84] and one in established SE [83], phenytoin was compared with valproate. These studies were assessed in a recent systematic review, showing that there was no detectable difference between valproate and phenytoin in clinical seizure cessation (RR 1.31, $95 \%$ CI 9.93-1.84), seizure freedom at $24 \mathrm{~h}$ (RR 0.96; $95 \% \mathrm{CI}$ $0.88-1.06$ ), but significantly more side effects with phenytoin (RR 0.31; $95 \%$ CI 0.12-0.85) [37]. The overall success rate with IV phenytoin has ranged from $44 \%$ in a randomized, controlled study to $90 \%$ in the uncontrolled studies [85]. It is important to consider that many of the patients in these studies had ineffective pretreatment with benzodiazepines, paraldehyde, or phenobarbital, making an estimate of the effect of phenytoin difficult to assess.

Fosphenytoin is a water-soluble precursor which is rapidly transformed to phenytoin. Advantages are a faster rate of infusion, up to $150 \mathrm{mg} / \mathrm{min}$ and a better local tolerability [86, 87]. Because of the 15 -min time to conversion from fosphenytoin to phenytoin a similar delayed action is expected [88]. Due to its very high costs, fosphenytoin is not on the formulary of most hospitals in Europe.

\subsection{Valproic Acid (IV)}

Valproic acid (or the sodium salt of it, i.e., valproate) is worldwide the most often prescribed AED [89]. It has a broad spectrum of efficacy, against all seizure types, and a well-known risk and adverse-event profile [90-94]. Several studies on the pharmacokinetics of IV valproate in healthy probands and patients with epilepsies are available [9597]. Maximum plasma concentrations were reached within minutes, and onset of action is quick. Valproic acid is highly bound to plasma protein $(>90 \%)$ and is extensively metabolized in the liver (glucuronidation and betaoxidation). The terminal half-life is $12 \mathrm{~h}$. Experimental data demonstrated a rapid and reliable onset of action in several SE models $[98,99]$. Since the introduction of IV valproate, experiences with this agent in 860 patients with various forms of $\mathrm{SE}$ have been reported, including six randomized, controlled trials, four non-randomized, controlled trials, and 20 uncontrolled trials (eight prospective, 12 retrospective) [100]. The overall response rate to 
abrogate SE was $70.9 \%$ (601/848; $95 \%$ CI 67.8-73.9) [100]. The most commonly used effective dose was $15-45 \mathrm{mg} / \mathrm{kg}$ as a bolus $(6-10 \mathrm{mg} / \mathrm{kg} / \mathrm{min})$ followed by $1-3 \mathrm{mg} / \mathrm{kg} / \mathrm{h}$ infusion [85, 100-104].

Valproic acid is non-sedating and has been used in critically ill patients with rapid infusions up to $40 \mathrm{mg} / \mathrm{kg} /$ min with good tolerability $[102,105]$. Safety studies of IV valproic acid in patients with SE showed a low incidence of adverse events overall $(<10 \%)$, mainly dizziness, thrombocytopenia, and mild hypotension, which was independent of infusion rates [100]. Of note is the good cardiovascular and respiratory tolerability. The most serious concern relates to the possibility of acute encephalopathy, which is sometimes related to hepatic abnormalities or hyperammonaemia $[89,93,106,107]$.

\subsection{Levetiracetam (IV)}

Levetiracetam is an efficacious and well tolerated drug with a broad spectrum of efficacy against all seizure types and a low potential for interactions due to minimal hepatic metabolism and low plasma protein binding $(<10 \%)$ [108110]. IV levetiracetam has been available since 2006. In animal experiments a rapid antiepileptic activity has been demonstrated, especially when used in combination with diazepam [111]. Retrospective case series and prospective safety studies on more than 1000 patients including more than 500 with various forms of SE have been reported [85, $112,113]$. The safety profile of levetiracetam is advantageous, with a very low rate of adverse effects reported (most often somnolence and sedation, and rarely agitation and thrombocytopenia) [113].

In a meta-analysis including ten studies (seven retrospective observational, two prospective observational, one prospective randomized control) reporting on 234 patients, efficacy ranged from 44 to $94 \%$, with a higher efficacy reported in the retrospective studies [114]. A recent metaanalysis on five different treatment options including levetiracetam in benzodiazepine-resistant SE identified 27 studies (798 patients with CSE) [115]. The relative effectiveness of levetiracetam was $68.5 \%$ (95\% CI 56.2-78.7), compared with phenobarbital $73.6 \% \quad(95 \%$ CI 58.3-84.8\%), phenytoin 50.2\% (95\% CI 34.2-66.1), and valproate $75.7 \%$ (95\% CI 63.7-84.8). The authors concluded that levetiracetam, valproate, or phenobarbital, but not phenytoin, should be used as first-line drugs in benzodiazepine-resistant SE [115].

Interestingly, although levetiracetam is considered a drug for the treatment of established SE, a recent randomized, open-labeled study compared its use with iIV lorazepam in 79 patients with early (stage I) SE [116]. Both drugs were equally effective in reaching clinical seizure cessation within $10 \mathrm{~min}$ of administration, with significantly higher respiratory failure requiring artificial ventilation among patients receiving lorazepam. This pilot study suggests that levetiracetam is also effective in earlystage SE, where it might represent an alternative to lorazepam.

\subsection{Phenobarbital (IV, IM)}

In a randomized, controlled trial on CSE, IV phenobarbital was at least as effective as a combination of diazepam and phenytoin [117]. In the Veterans Affairs-study phenobarbital was not inferior to lorazepam in the initial treatment of SE [81]. The central depressive effect of phenobarbital, especially following the use of benzodiazepines, limits its clinical utility, when alternatives are available. However, over the years wide experience has been gained in adults and children, as well as in the newborn. The main disadvantages are sedation, respiratory depression, and hypotension. The usual recommended adult IV loading dose of phenobarbital is $10 \mathrm{mg} / \mathrm{kg}$ (doses up to $20 \mathrm{mg} / \mathrm{kg}$ have been used and recommended) given at the rate of $100 \mathrm{mg} / \mathrm{min}$, up to a total amount of $700 \mathrm{mg}$ in $7 \mathrm{~min}$. In the acute setting respiration and blood pressure have to be monitored and the patient has to be under clinical observation.

\section{Refractory Status Epilepticus: Stage III}

After failure of stage I treatment (with benzodiazepines) and failure of stage II treatment (with phenytoin, levetiracetam, or valproic acid), 31-43\% of patients enter the refractory stage $[118,119]$. In refractory and super-refractory SE, IV anesthetic drugs (thiopental/pentobarbital, midazolam, or propofol) are commonly used [28]. Treatment recommendations at this stage depend on retrospective case series and uncontrolled studies [120-122]. In two systemic reviews, none of the treatments currently available was superior to another [123, 124]. Propofol may be associated with an infusion syndrome, characterized by metabolic acidosis, rhabdomyolysis, renal failure, and heart failure [125]. Treatment duration of less than $48 \mathrm{~h}$ and doses of no more than $5 \mathrm{mg} / \mathrm{kg} / \mathrm{h}$ are recommended. The rate of cardiovascular and metabolic complications seemed to be lowest with midazolam and highest with barbiturates, which cause a severe immunosuppression, and often lead to infections in the compromised patient $[123,124]$. The use of anesthetics in refractory and super-refractory SE was associated with more infections during SE (43\% vs. $11 \%$; $p=0.0001)$ and a 2.9-fold relative risk for death (2.88; $95 \%$ CI 1.45-5.73) in a 6-year prospective cohort study including 171 patients (63 of them received IV anesthetics) [126]. 


\subsection{Midazolam (Continuous IV Infusion)}

One study compared continuous IV midazolam infusion versus continuous IV diazepam infusion in patients with refractory SE defined as seizures not controlled by two bolus doses of diazepam $(0.3 \mathrm{mg} / \mathrm{kg})$ and phenytoin infusion $(20 \mathrm{mg} / \mathrm{kg}$ in normal saline infusion over $20 \mathrm{~min}$ ) followed by a repeat dose of benzodiazepine [127]. Continuous midazolam and diazepam infusions were equally effective for cessation of SE, although midazolam was associated with a higher seizure recurrence rate and mortality. About half of the patients required mechanical ventilation and $40 \%$ of patients in both groups had hypotension. In a recent study, highdose continuous IV midazolam $(n=100)$ was compared with a historical control of the same center treated with a lower dose $(n=29)$ [128]. The median maximum dose was $0.4 \mathrm{mg} / \mathrm{kg} / \mathrm{h}$ (interquartile range [IQR] $0.2,1.0$ ) for the high-dose group and $0.2 \mathrm{mg} / \mathrm{kg} / \mathrm{h}$ (IQR $0.1,0.3$ ) for the low-dose [128] group $(p<0.001)$, with a similar duration of infusion. Withdrawal seizures, occurring within $48 \mathrm{~h}$ of discontinuation of continuous midazolam infusion, were less frequent in the high-dose group (15 vs. $64 \%$; odds ratio (OR) $0.10 ; 95 \%$ CI $0.03-0.27$ ) and discharge mortality was lower in the high-dose group (40 vs. $62 \%$; OR 0.34 ; $95 \%$ CI $0.13-0.92$ ) compared with the low-dose group.

\subsection{Propofol}

Propofol is an anesthetic agent, acting as an $\mathrm{N}$-methyl-Daspartate (NMDA) antagonist in vitro [129], with a shorter duration of action and lower tendency to accumulate in the body than barbiturates. It may cause hypotension, but reduces intracranial pressure and brain metabolic requirements [130], and may also have immunomodulatory effects [131]. Its prolonged use has been reported to cause the socalled "propofol infusion syndrome," which includes potentially fatal myocardial failure with lactic acidosis, hypertriglyceridemia, and rhabdomyolysis, with an observed incidence of around $1 \%$ [132-134].

Propofol has been directly compared with thiopental sodium (see Sect. 4.3) in a small (only 24 patients recruited of the 150 needed; 14 subjects received propofol, nine thiopental), single-blind, multicenter trial evaluating adult patients with refractory SE [135]. This study showed a wide CI, suggesting that the drugs may differ in efficacy up to more than twofold. No difference was found between the drugs with respect to control of seizure activity and return to baseline clinical conditions at 3 months. Infections and arterial hypotension did not differ between groups, although thiopental use was associated with significantly longer mechanical ventilation.
To date, robust evidence on the role of propofol based on large, randomized, controlled trials for this serious condition is still lacking [136].

\subsection{Thiopental, Pentobarbital}

Thiopental sodium and pentobarbital are barbiturates acting as GABA-A agonists, with enhanced inhibitory neurotransmission and antiepileptic action. Both drugs have a prolonged duration of action, mainly due to their accumulation in the body, resulting in a long recovery time [137]. Furthermore, they may cause hypotension and cardiorespiratory depression, which may require the use of additional drugs to control pressure and breathing, as well as immunosuppression [138-140].

As reported earlier (Sect. 4.2), compared with propofol, the use of thiopental seems to be associated with longer mechanical ventilation, with no difference with respect to control of seizure activity, infections, and arterial hypotension [135].

A systematic review evaluated the outcomes of anesthetics (thiopental/pentobarbital, $n=192$; midazolam, $n=585$; propofol, $n=143$ ) for terminating refractory and super-refractory SE. Barbiturate treatment achieved seizure control in $64 \%$ (midazolam $78 \%$, propofol $68 \%$ ), but was associated with death rate during treatment in $19 \%$ (midazolam $2 \%$, propofol $8 \%$ ). The authors concluded that a treatment protocol for stages III and IV of SE divided into first-line, second-line, and third-line therapy is suggested on the basis of their outcome evaluation [124]. Thus, barbiturates should be restricted to the most severe forms of refractory SE.

Despite the wide use of barbiturate anesthesia for the treatment of refractory SE, evidence derived from comparative randomized, controlled trials on the efficacy of barbiturates on which to base a choice is still lacking.

\subsection{Isoflurane (Inhalation)}

Isoflurane is an inhalational anesthetic acting by enhancing GABA activity, with subsequent increased inhibitory neurotransmission. In a case series, this drug (used for up to $55 \mathrm{~h}$ ) led to seizure cessation in nine patients, although with a mortality rate of $67 \%$ [141]. A subsequent study reported its use in seven patients with refractory SE (defined as "continued seizures after failure of two or three antiepileptic drugs") [142]: isoflurane consistently stopped epileptic discharges with adequate, sustained suppression of electroencephalographic bursts within minutes of administration. Complications were common: all patients developed severe hypotension requiring vasopressors and atelectasis; paralytic ileus occurred in three patients; and the outcome was fatal in three patients. No renal or hepatic 
Fig. 2 Example of a treatment protocol for super-refractory status epilepticus (SE).

Modified after Meierkord et al. [32]. AEDs antiepileptic drugs, $C S F$ cerebrospinal fluid, $E C T$ electroconvulsive therapy, $E E G$ electroencephalogram, $I V$ intravenous
Stage III and IV: General anaesthesia (continuous IV midazolam, pentobarbital/thiopental, propofol) $>24 \mathrm{~h}$

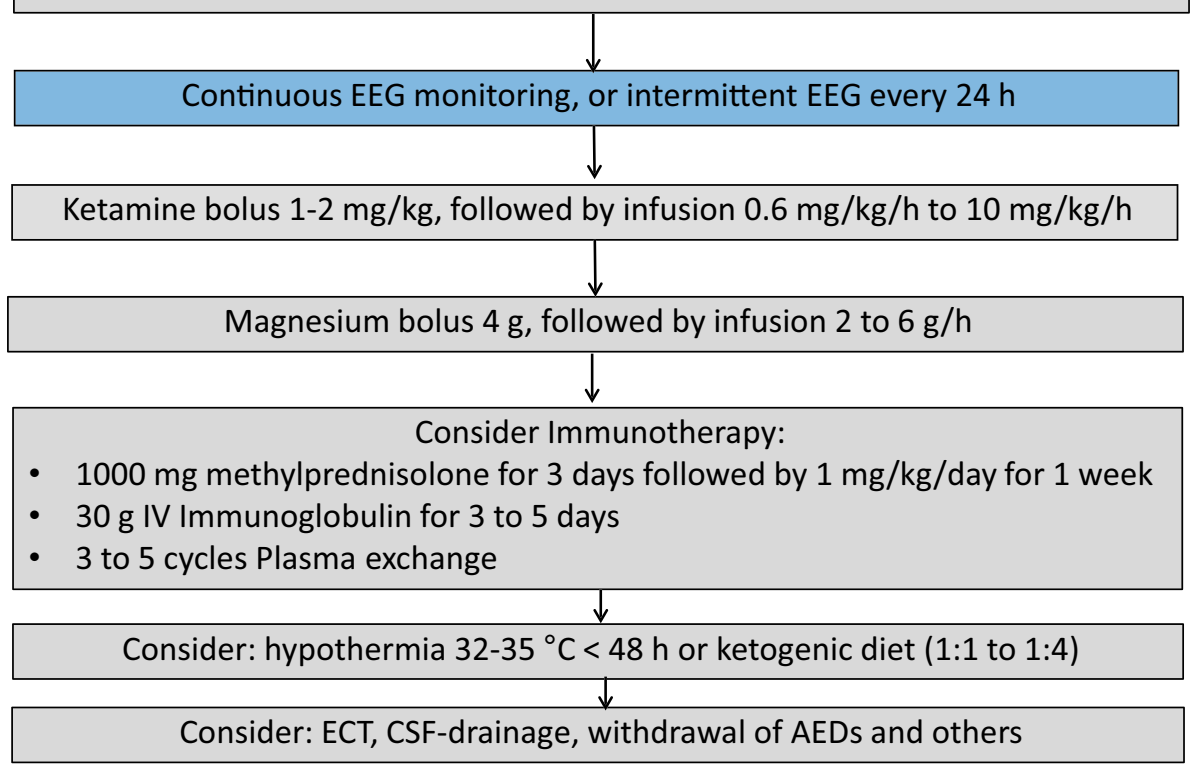

dysfunction occurred. Traditionally the use of inhalational anesthetics needed a vaporizer and a cart, which was not practical in the crowded environment of most intensive care units. The recently developed small self-contained vaporizers have become more widely available and will make the use of inhalational anesthetics in intensive care units more feasible.

\subsection{Etomidate (IV)}

Etomidate is an anesthetic for which the exact mechanism of action is unknown. It has a favorable safety profile with regard to cardiovascular side effects, and may induce sedation rapidly [143]. However, its use is limited by a concern for reversible cortisol inhibition occurring after the administration of this drug, which requires hormonal substitution during treatment with etomidate [144]. In a case series (eight patients), rapid control of seizure activity was obtained in all cases, with hypotension occurring in five subjects [145].

\section{Super-Refractory Status Epilepticus: Stage IV}

When treatment with an IV anesthetic for more than $24 \mathrm{~h}$ is not successful in controlling SE, the condition can be termed super-refractory SE or malignant SE [28]. There have been no studies of this stage, and evidence is extremely sparse. A new initiative of a global audit (http://www. status-epilepticus.net) is aimed at gaining more information on the treatments used and outcomes achieved at this stage of SE. Recommendations are based exclusively on small case series, including several treatment options, such as ketamine, corticosteroids, magnesium, IV immunoglobulin, a ketogenic diet, and neurostimulation, and in lesional cases, also surgery. It is advised to establish a protocoldriven treatment approach (Fig. 2).

\subsection{Ketamine (IV infusion)}

Ketamine has a strong antagonistic effect on the NMDAglutamate receptor. It has a half-life of $2-3 \mathrm{~h}$ and is extensively metabolized by the hepatic cytochrome $\mathrm{P} 450$ pathway to its active metabolite, norketamine [146]. Animal models (hippocampal electrical stimulation or pilocarpine animal models) have demonstrated the efficacy of ketamine in refractory SE in rats, even in late stages [146-148].

To date, there are two retrospective case series [149, $150]$ and nine single case reports, reporting 80 episodes of refractory SE in adults treated with ketamine [151-159].

One retrospective case series included 46 adults and 12 children, with 60 episodes of refractory SE. The outcome data for adults has not been separated from children [150].

In total 23 CSE, 13 NCSE, five focal SE, 38 focal NCSE, and one SE of infantile spasms were treated with ketamine. The overall success rate was $56 \%$ after treatment with ketamine. The bolus dose ranged from 0.5 to $2 \mathrm{mg} / \mathrm{kg}$ [151, 157]. In three case reports no bolus was administered [155, 159, 160].

In the case series the loading dose varied from 1 to $2 \mathrm{mg} / \mathrm{kg}[149,150]$, and the subsequent infusion rate ranged from $0.6 \mathrm{mg} / \mathrm{kg} / \mathrm{h}$ to a maximal $10 \mathrm{mg} / \mathrm{kg} / \mathrm{h}[150,153]$. The treatment duration of ketamine was at least $2 \mathrm{~h}$ [152] 
and at most 27 days [150]. The time of SE until ketamine administration was started ranged from a few hours [152] up to 140 days [155]. A median of five medications (min four, max nine) prior to ketamine were used.

With regard to adverse events, one patient suffered from dysarthria, drooling, and appendicular ataxia after treatment with ketamine; upon magnetic resonance imaging a cerebellar atrophy was described. The authors concluded this to be a neurotoxic effect of ketamine. In comparison with other reports they used a higher loading - and a higher infusion dose of ketamine $(2 \mathrm{mg} / \mathrm{kg}$ and a maximum dose of $7.5 \mathrm{mg} / \mathrm{kg} / \mathrm{h}$ ). After a follow-up of 21 months there was a slight clinical improvement [157].

One patient suffered from hypertension, with systolic blood pressure $>220 \mathrm{mmHg}$ for $10 \mathrm{~min}$, after the initial bolus of $0.5 \mathrm{mg} / \mathrm{kg}$ was administered [154]. In one case series a patient had symptoms like propofol-infusion syndrome after 4 days of high-dose ketamine $(4.5 \mathrm{mg} / \mathrm{kg} / \mathrm{h})$ and midazolam, and recovered after discontinuation. Another two patients developed supraventricular tachycardia [150]. A systematic review evaluating efficacy in pediatrics and adults showed that currently there exists Oxford level 4, Grade C evidence to support the use of ketamine for refractory SE. But they believe that there is a potential benefit with low adverse effects of NMDA antagonists - further prospective studies of early ketamine administration are needed [159].

\subsection{Magnesium (IV)}

Magnesium sulphate probably has an antiepileptic action through blocking the NMDA receptor. Magnesium sulphate has been used in SE since 1901, but has not gained much attention until now. It is currently used as the drug of choice in treating seizures occurring in eclampsia [161]. The evidence on its use in patients with SE is based on single case reports, with some evidence of benefit [162, 163]. To date, no comparative study has been conducted to assess its role in SE management. However, its infusion is safe and without significant adverse events. It has been suggested to administer magnesium as an initial IV bolus, followed by a continuous infusion at a dose that increases the serum level to $\sim 3.5 \mathrm{mmol} / \mathrm{L}$ [163].

\subsection{Topiramate (Enteral)}

Topiramate is a broad-spectrum AED with several mechanisms of action, including blockade of the ionotropic glutamatergic AMPA receptor [164]. There is no commercially available IV formulation, but it can be administered enterally.

Evidence on the use of topiramate in super-refractory SE is based on 95 patients reported to date in the literature
[124, 165]. The dose of topiramate used in studies ranged between 2 and $25 \mathrm{mg} / \mathrm{kg} /$ day in children and up to $1600 \mathrm{mg} /$ day in adults, leading to clinical seizure cessation in $62 / 95(65 \%)$ of patients. Metabolic acidosis was the most frequently reported side effect with its use.

\subsection{Immunotherapy: Corticosteroids, IV Immunoglobulins, Plasma Exchange}

The recent discovery that super-refractory SE may be caused by antibodies against neural cell receptors (voltagegated potassium and $N$-methyl-D-aspartate (NMDA)) and evidence on the role of inflammation in epileptogenesis [166-168] led to the increasing use of immunotherapy in this stage of SE, even in the absence of any defined immunologic disease. However, to date no single comparative study has been conducted to evaluate the efficacy and tolerability of immunotherapies in super-refractory SE, and evidence is based on more than 50 patients treated so far [28]. In all reported cases, other therapies were also introduced concurrently, so that it is extremely difficult to definitively dissect the antiepileptic efficacy of immunotherapy from that of other treatments.

The rationale for the use of immunotherapies is that in some cases super-refractory SE without a clear underlying cause might be due to occult immunologic diseases with antibodies (not yet identified) directed against neural elements, which may also explain the persistence of the SE. Consequently, even in the absence of an immunologic underlying cause for the SE, a trial of high-dose steroids (1 $\mathrm{g}$ of IV prednisolone/day for 3 days followed by $1 \mathrm{mg} /$ $\mathrm{kg}$ /day for $\sim 1$ week) can be given. In case of no efficacy within 2 days, either IV immunglobulins (at a dose of $0.4 \mathrm{~g} / \mathrm{kg}$ over 5 days) or plasma exchange can be tried in addition. If there is a response, treatment is continued with long-term corticosteroids, repeated courses of IV immunoglobulins and, later, other immunomodulatory agents such as cyclophosphamide or rituximab [28].

\section{Other Drugs Used in Status Epilepticus}

\subsection{Lacosamide (IV)}

Lacosamide has been available since 2008 in the European Union for the treatment of focal epilepsies [169-171]. Bioequivalence studies in healthy probands and adults with epilepsy report a good tolerability of the IV solution [172, 173]. In animal models on SE, lacosamide demonstrated a good efficacy [174]. First case reports and retrospective case series on lacosamide were published shortly after availability of the IV formulation [175-178]. There are in total 19 studies (ten single case reports and nine case 
series), reporting a total of 136 episodes of refractory SE (50\% NCSE, $31 \%$ focal SE, and $19 \% \mathrm{CSE}$ ) treated with lacosamide [176]. All retrospective case series included patients with various forms of SE in different stages. The most commonly used bolus dose was $400 \mathrm{mg}$, followed by a daily dose of 200-400 mg lacosamide. The overall success rate was $56 \%$ (76/136). Adverse events were reported in $25 \%(34 / 136)$ of patients: mild sedation in 25 cases, one patient with possible angioedema, two with allergic skin reactions, four with hypotension, and one with pruritus. One patient developed a third-degree atrioventricular (AV) block and paroxysmal asystole [176]. There are also two single case reports (one in a patient with NCSE, one with neuropathy), reporting on AV-conduction abnormalities associated with an application of the drug [179, 180]. There was a small increase in PR interval at the end of the infusion reported in the bioequivalence studies, but this was judged to be clinically not relevant $[172,173]$.

\subsection{Paraldehyde (IM, Rectal)}

Paraldehyde is a drug with proven anticonvulsant properties both in animal models [181] and in humans [182]. It acts through a mechanism not yet identified, and appears to be safe with regard to cardiovascular tolerability [143]. The rectal route, which is less painful and carries no risk of sterile abscess, has largely replaced the traditional IM injection [182].

In one pediatric study rectal paraldehyde was found to be effective in terminating over $60 \%$ of acute and prolonged convulsive seizure episodes within $10 \mathrm{~min}$ of its administration and without any documented adverse side effects [182]. A similar finding (clinical seizure cessation within $10 \mathrm{~min}$ of its administration) was found in a subsequent open-label randomized, controlled clinical trial comparing IN lorazepam and IM paraldehyde in children with prolonged (>5 min) tonic-clonic seizures; no clinically important cardiorespiratory events were reported with IM paraldehyde [183]. Of note, in this study IN lorazepam was more effective (i.e., less likely to require additional drugs to terminate seizure), significantly safer, and cheaper than IM paraldehyde in the treatment of acute tonic-clonic seizures.

\subsection{Lidocaine (IV)}

Lidocaine acts as a local anesthetic drug by inhibiting ionic currents through voltage-gated sodium channels during abnormal membrane depolarization [184]. Interestingly, IV lidocaine has been widely used in Japan for the treatment of CSE, although this drug has no official approval for the management of this condition. Most studies assessing its role in SE were performed in Japan [185, 186]. To date, there are no large, double-blind, placebo-controlled studies evaluating lidocaine in SE, although numerous case reports and case series support its use [185-188]. Most of the available data derive from patients refractory to multiple AEDs. Furthermore, additional data supporting the use of lidocaine in SE come from pediatric uncontrolled studies, where this drug proved effective in controlling SE in neonates not responding to barbiturates [187, 188].

Overall effectiveness of lidocaine in cessation of CSE ranges between $35.8 \%$ and $53 \%$ [187-190]. Furthermore, unlike other AEDs used for the treatment of SE carrying the risk of respiratory depression, lidocaine has been reported to reduce the rate of mechanical ventilation [187].

\subsection{Chlormethiazole (IV)}

Chlormethiazole (clomethiazole) is a thiazole derivative acting by enhancing GABA activity, with subsequent increased inhibitory neurotransmission. No controlled studies have been conducted to evaluate its effectiveness and tolerability in SE. To date, only a few reports of patients with SE (mostly children) treated with IV chlormethiazole are available [191-194], so that the evidence supporting its use in SE is scarce. Several adverse effects related to its use have been reported including thrombophlebitis and respiratory depression [195].

\subsection{Carbamazepine (Rectal, IV)}

Carbamazepine has ILAE level A evidence for treatment of adults with focal epilepsy. This drug is characterized by poor water solubility, which represents an obstacle in the development of a parenteral formulation. IV carbamazepine has been tested in animal models [196, 197], showing rapid onset of anticonvulsant action and lack of respiratory or cardiovascular adverse effects, and very recently also in humans [198-200]. Novel IV formulations with favorable pharmacokinetics have been developed [201], but their use in clinical practice needs to be definitively assessed.

To date, there is no study reporting on patients with SE treated with IV carbamazepine. However, there is a case series reporting on seven patients presenting with cluster seizures or generalized tonic-clonic SE, who received a rectally administered oral syrup of carbamazepine with subsequent measurement of serum levels (the goal was to achieve minimum therapeutic levels of total carbamazepine $>20 \mu \mathrm{mol} / \mathrm{L}$ ) [202]. In all patients seizures had terminated prior to administration of carbamazepine, but no patient had a seizure recurrence after carbamazepine administration. This study therefore indicates the potential long-acting efficacy of rectal carbamazepine in achieving maintenance of freedom from seizures in patients with SE, but does not support its use in terminating SE. 


\section{Conclusions}

In this article, we reviewed the pharmacotherapy of SE according to a staged approach based on pragmatic definitions. Morbidity and mortality correlate with duration of epileptic activity, the rapid identification of the cause of SE, age, and comorbidity of the patients [9, 10, 203-206]. Indeed, if left untreated, SE is potentially fatal or can lead to irreversible brain damage.

There is general agreement that treatment of status should follow a staged treatment protocol, so that patients may receive prompt and appropriate treatment [30]. Despite conflicting data [207], clinical seizure cessation seems to be clearly associated with adherence to treatment protocols [208-210]. Yet many hospitals do not have these or do not review and update them regularly. Randomized, controlled trials show that IV lorazepam [40, 41, 81] or IM midazolam $[44,211,212]$ are the most efficient drugs in early-stage SE.

Midazolam buccal administration is a widely used alternative first-line treatment for emergency management of acute seizure disorders by non-medical personnel, prior to admission to hospital. The IN route may also be used for early SE, particularly in children, but its value compared with the buccal or IM routes is less established. Compared to lorazepam or midazolam, diazepam is more widely available throughout the world, representing a valuable alternative to lorazepam for early SE. However, compared to lorazepam, diazepam undergoes a rapid redistribution with subsequent shorter duration of action, and higher risk of accumulation after repeated administration. Rectal diazepam administration is a valuable therapeutic alternative to IV diazepam or lorazepam when this method of administration is not feasible, as it often occurs in prehospital settings without skilled health-care personnel. However, buccal or IN midazolam represent alternatives that are more socially accepted than rectal diazepam.

Approximately $30-40 \%$ of all patients do not respond to benzodiazepines administered as first-line drugs, needing further treatment with IV AEDs. Even with their use, a high proportion of patients remain refractory, requiring the use of anesthetics [81, 85, 213, 214]. IV phenytoin or phenobarbital are widely used treatments for established SE. However, phenytoin and phenobarbital are not efficacious in some epilepsy syndromes and there are several concerns related to their safety profile, as both drugs may cause cardiac arrhythmias, hypotension, and respiratory depression, the latter being aggravated by co-administration with benzodiazepines.

Hence, IV formulations of other AEDs, including valproate, levetiracetam, and lacosamide have generated considerable interest as possible treatments for established SE after failure of benzodiazepines [100, 112, 113, 176$178,215]$.
Classic randomized clinical trials satisfying contemporary standards are extremely challenging to perform in the setting of established SE. To date there are no class I data to support treatment recommendations for most AEDs that may be used for established, refractory, and super-refractory SE. The only partial exception concerns the evidence for use of IV valproate in the treatment of established SE, which has been shown to have a similar efficacy but a better tolerability than phenytoin in a meta-analysis [37, 100]. A recent systematic review compared the relative efficacy of five AEDs in treatment of stage II, benzodiazepine-resistant CSE [115]. Valproate was effective in controlling SE in $75.7 \%$ (95 \% CI 63.7-84.8), levetiracetam in $68.5 \%$, (95\% CI 56.2-78.7), phenobarbital in $73.6 \%$ (95\% CI 58.3-84.8), and phenytoin in 50.2\% (95\% CI 34.2-66.1). Considered overall, cumulative data from the literature are therefore consistent with valproate and levetiracetam being a safe and effective therapeutic alternative to phenobarbital and phenytoin for treatment of established SE persisting despite conventional first-line treatment with benzodiazepines. A high-class randomized, controlled trial comparing valproate, levetiracetam, and phenytoin for established SE (ESET Trial) is underway, and the first results can be expected in the next few years [216]. Limiting the methodological heterogeneity across studies will be of the utmost importance in further research in the treatment of SE: investigators should adopt uniform definitions of SE and its different stages, provide individual patient data, and report their results clearly and explicitly.

\section{Compliance with Ethical Standards}

Funding There was no funding related to the preparation of this article.

Conflicts of interest Eugen Trinka has acted as a paid consultant to Eisai, Ever Neuropharma, Biogen Idec, Medtronics, Bial, and UCB and has received speakers' honoraria from Bial, Eisai, GL Pharma, GlaxoSmithKline, Boehringer, Viropharma, Actavis, and UCB Pharma in the past 3 years. Eugen Trinka has received research funding from UCB Pharma, Biogen Idec, Red Bull, Merck, the European Union, FWF Österreichischer Fond zur Wissenschaftsförderung, and Bundesministerium für Wissenschaft und Forschung. Eugen Trinka is also part of the investigators planning the ESET-Trial and member of the Task Force on Classification of Status Epilepticus of the ILAE. Julia Höfler has received speakers' honoraria from UCB Pharma and travel support from Eisai and GL Pharma. Markus Leitinger has received travel grants from Medtronics. Francesco Brigo has received speaker's honoraria from UCB Pharma.

Open Access This article is distributed under the terms of the Creative Commons Attribution-NonCommercial 4.0 International License (http://creativecommons.org/licenses/by-nc/4.0/), which permits any noncommercial use, distribution, and reproduction in any medium, provided you give appropriate credit to the original author(s) and the source, provide a link to the Creative Commons license, and indicate if changes were made. 


\section{Appendix}

\section{Early Status Epilepticus: Stage I}

Intravenous (IV) route available:

- Lorazepam $0.07 \mathrm{mg} / \mathrm{kg}$ (usually $4 \mathrm{mg}$ ) IV bolus (maximum rate $2 \mathrm{mg} / \mathrm{kg}$ ); if necessary can be repeated once.

OR

- Diazepam 5-10 mg IV bolus (maximum rate $5 \mathrm{mg}$ / $\mathrm{min}$ ); if necessary can be repeated once up to $20 \mathrm{mg}$.

OR

- Clonazepam $1 \mathrm{mg}$ IV bolus (maximum rate $0.5 \mathrm{mg}$ / $\mathrm{min}$ ); if necessary can be repeated once after $5 \mathrm{~min}$.

If IV route is difficult or not possible:

- Midazolam $10 \mathrm{mg}$ buccal $(5 \mathrm{mg}$ in the elderly or in patients $<50 \mathrm{~kg}$ ); if necessary can be repeated once after $10 \mathrm{~min}$. Alternatively, use $10 \mathrm{mg} / 2 \mathrm{~mL}$ injection via buccal route.

OR

- Midazolam $10 \mathrm{mg}$ intramuscularly (5 $\mathrm{mg}$ in the elderly or in patients $<50 \mathrm{~kg}$ ); if necessary can be repeated once after $10 \mathrm{~min}$.

OR

- Diazepam $10 \mathrm{mg}$ rectal $(5 \mathrm{mg}$ in the elderly or in patients $<50 \mathrm{~kg}$ ); if necessary can be repeated once after $10 \mathrm{~min}$.

\section{Established Status Epilepticus: Stage II}

- Phenobarbital $10 \mathrm{mg} / \mathrm{kg}$ (range 10-20) IV bolus infusion at a max. rate of $100 \mathrm{mg} / \mathrm{min}$.

OR

- Phenytoin $18 \mathrm{mg} / \mathrm{kg}$ (range 15-20) IV bolus infusion at max. rate of $50 \mathrm{mg} / \mathrm{min}$.

OR

- Fosphenytoin $15 \mathrm{mg} \mathrm{PE} / \mathrm{kg}$ (range 15-20) IV bolus infusion at max. rate of $100 \mathrm{mg} \mathrm{PE} / \mathrm{min}$.

OR

- Valproate $30 \mathrm{mg} / \mathrm{kg}$ (range 15-30) IV bolus infusion at $3-6 \mathrm{mg} / \mathrm{kg} / \mathrm{min}$.

OR
- Levetiracetam* $30 \mathrm{mg} / \mathrm{kg}$ (range 30-60) IV bolus infused over $10 \mathrm{~min}$.

OR

- Lacosamide* 200-400 mg IV bolus infused over 3-5 min.

\section{Refractory Status Epilepticus: Stage III}

The following drugs need to be administered by a neurointensivist/experienced anaesthetist in an intensive care unit setting:

- Propofol $2 \mathrm{mg} / \mathrm{kg}$ IV bolus infusion, repeated if necessary, and then followed by a continuous infusion of $5-10 \mathrm{mg} / \mathrm{kg} / \mathrm{h}$ initially, reducing to a dose sufficient to maintain a burst-suppression pattern on the EEG (usually $1-3 \mathrm{mg} / \mathrm{kg} / \mathrm{h}$ ).

OR

- Thiopental 100-250 mg IV bolus infusion giver over $20 \mathrm{~s}$ with further $50-\mathrm{mg}$ boluses every $2-3 \mathrm{~min}$ until seizure control, followed by a continuous IV infusion at a dose sufficient to maintain a burst-suppression pattern on the EEG (usually $3-5 \mathrm{mg} / \mathrm{kg} / \mathrm{h}$ ).

OR

- Pentobarbital 5-15 mg/kg IV bolus, followed by a continuous IV infusion at a dose sufficient to maintain a burst-suppression pattern on the EEG (usually $0.5-3 \mathrm{mg} / \mathrm{kg} / \mathrm{h}$ ).

OR

- Midazolam $0.1-0.3 \mathrm{mg} / \mathrm{kg}$ IV bolus infusion at max. rate of $4 \mathrm{mg} / \mathrm{min}$ initially, followed by a continuous IV infusion at a dose sufficient to maintain a burstsuppression pattern on the EEG (usually $0.05-0.4 \mathrm{mg} /$ $\mathrm{kg} / \mathrm{h})$.

After seizure control has been achieved for at least $12 \mathrm{~h}$, the drug dosage should be slowly reduced over a further $12 \mathrm{~h}$. If seizures recur, the anesthetic agent should be administered again for another $12 \mathrm{~h}$, and then withdrawal attempted again. This cycle may need to be repeated every $24 \mathrm{~h}$ until achievement of seizure control.

Continuous EEG monitoring is indicated to assess level of anesthesia (burst-suppression pattern) and abolition of ictal discharges after drug withdrawal

\section{Super-Refractory Status Epilepticus: Stage IV}

No randomized, controlled trials are available in the literature to inform about the use of any drug in the treatment of super-refractory status epilepticus.

Maintain the use of anesthetic drugs used in stage III. 
Consider the use of:

- Ketamine* 1-3 mg/kg IV bolus, followed by a continuous IV infusion at a dose sufficient to maintain a burst-suppression pattern on the EEG (usually up to $5 \mathrm{mg} / \mathrm{kg} / \mathrm{h}$ ).

As second-line therapy [124] consider:

- Hypothermia* levels of hypothermia uncertain, usually target temperatures between 32 and $35^{\circ} \mathrm{C}$ continued in the first instance for 24-48 h;

- Magnesium infusion* dose of $2-6 \mathrm{~g} / \mathrm{h}$ to obtain a serum level of $3.5 \mathrm{mmol} / \mathrm{L}$;

- Pyridoxine infusion* (in young children): 180-300 mg;

- Immunologic therapy* high-dose steroids $(1 \mathrm{~g} /$ day in adults) over 3 days and continued at lower doses $(1 \mathrm{mg} / \mathrm{kg} /$ day) over 1 week; in addition, course of IV immunoglobulin $(0.4 \mathrm{~g} / \mathrm{kg} /$ day $)$ over 5 days or plasma exchange;

- Ketogenic diet*;

- Emergency neurosurgery* (including focal resection, multiple subpial transection, corpus callosotomy, and hemispherectomy, even in combination).

As third-line therapy [124] consider:

- Electroconvulsive therapy*;

- Cerebrospinal fluid drainage*.

*No randomized, controlled trials available in the literature to inform about the use of this drug/procedure in this stage of status epilepticus.

Ferlisi and Shorvon [124].

\section{References}

1. Lowenstein DH, Bleck T, Macdonald RL. It's time to revise the definition of status epilepticus. Epilepsia. 1999;40(1):120-2.

2. Bauer G, Trinka E. Nonconvulsive status epilepticus and coma. Epilepsia. 2010;51(2):177-90.

3. Drislane FW. Presentation, evaluation, and treatment of nonconvulsive status epilepticus. Epilepsy Behav. 2000;1(5):301-14.

4. Trinka E, Hesdorffer D, Rossetti AO, Scheffer I, Shinnar S, Shorvon S, Lowenstein D. A definition and classification of status epilepticus - report of the task force on classification of status epilepticus. Epilepsia. 2015. doi:10.1111/epi.13121.

5. Logroscino G, Hesdorffer DC, Cascino G, Annegers JF, Hauser WA. Time trends in incidence, mortality, and case-fatality after first episode of status epilepticus. Epilepsia. 2001;42(8):1031-5.

6. Logroscino G, Hesdorffer DC, Cascino G, Hauser WA, Coeytaux A, Galobardes B, Morabia A, Jallon P. Mortality after a first episode of status epilepticus in the united states and europe. Epilepsia. 2005;46(Suppl 11):46-8.
7. Logroscino G, Hesdorffer DC, Cascino GD, Annegers JF, Bagiella E, Hauser WA. Long-term mortality after a first episode of status epilepticus. Neurology. 2002;58(4):537-41.

8. Sokic DV, Jankovic SM, Vojvodic NM, Ristic AJ. Etiology of a short-term mortality in the group of 750 patients with 920 episodes of status epilepticus within a period of 10 years (1988-1997). Seizure. 2009;18(3):215-9.

9. Sutter R, Marsch S, Fuhr P, Ruegg S. Mortality and recovery from refractory status epilepticus in the intensive care unit: A 7-year observational study. Epilepsia. 2013;54(3):502-11.

10. Leitinger M, Holler Y, Kalss G, Rohracher A, Novak HF, Hofler J, Dobesberger J, Kuchukhidze G, Trinka E. Epidemiologybased mortality score in status epilepticus (emse). Neurocrit care. 2015;22(2):273-82.

11. DeLorenzo RJ, Pellock JM, Towne AR, Boggs JG. Epidemiology of status epilepticus. J Clin Neurophysiol. 1995;12(4):316-25.

12. Waterhouse EJ, DeLorenzo RJ. Status epilepticus in older patients: Epidemiology and treatment options. Drugs Aging. 2001;18(2):133-42.

13. Knake S, Rosenow F, Vescovi M, Oertel WH, Mueller HH, Wirbatz A, Katsarou N, Hamer HM. Incidence of status epilepticus in adults in germany: a prospective, populationbased study. Epilepsia. 2001;42(6):714-8.

14. Hesdorffer DC, Logroscino G, Cascino G, Annegers JF, Hauser WA. Incidence of status epilepticus in rochester, minnesota, 1965-1984. Neurology. 1998;50(3):735-41.

15. Vignatelli L, Rinaldi R, Galeotti M, de Carolis P, D'Alessandro R. Epidemiology of status epilepticus in a rural area of northern italy: A 2-year population-based study. Eur J Neurol. 2005;12(11):897-902.

16. Vignatelli L, Tonon C, D’Alessandro R. Bologna Group for the Study of Status E: Incidence and short-term prognosis of status epilepticus in adults in bologna, italy. Epilepsia. 2003;44(7):964-8.

17. Chin RF, Neville BG, Scott RC. A systematic review of the epidemiology of status epilepticus. Eur J Neurol. 2004;11(12):800-10.

18. Neville BG, Chin RF, Scott RC. Childhood convulsive status epilepticus: epidemiology, management and outcome. Acta Neurol Scand. 2007;115(4):21-4.

19. DeLorenzo RJ, Towne AR, Pellock JM, Ko D. Status epilepticus in children, adults, and the elderly. Epilepsia. 1992;33(Suppl 4):S15-25.

20. Litt B, Wityk RJ, Hertz SH, Mullen PD, Weiss H, Ryan DD, Henry TR. Nonconvulsive status epilepticus in the critically ill elderly. Epilepsia. 1998;39(11):1194-202.

21. Sung CY, Chu NS. Status epilepticus in the elderly: etiology, seizure type and outcome. Acta Neurologica Scandinavica. 1989;80:51-6.

22. Towne AR. Epidemiology and outcomes of status epilepticus in the elderly. Int Rev Neurobiol. 2007;81:111-27.

23. Shorvon SD, Trinka E, Walker MC. The proceedings of the first London colloquium on status epilepticus-University College London, April 12-15, 2007. Introduction. Epilepsia. 2007;48(Suppl 8):1-3.

24. Wolf P, Trinka E, Bauer G. Absence status epilepticus: The first documented case? Epilepsia. 2007;48(Suppl. 8):4-5.

25. Clark LP, Prout TP. Status epilepticus: a clinical and pathological study in epilepsy [part1]. Am J Insanity. 1903;60:291-306.

26. Clark LP, Prout TP. Status epilepticus: a clinical and pathological study in epilepsy [an artical in 3 parts.]. Am J Insanity. 1903;60:291-306, 260, 645-675, 261, 281-108. 
27. Clark LP, Prout TP. Status epilepticus: a clinical and pathological study in epilepsy [part 3]. Am J Insanity. 1904;61:81-108.

28. Shorvon S, Ferlisi M. The treatment of super-refractory status epilepticus: a critical review of available therapies and a clinical treatment protocol. Brain. 2011;134(Pt 10):2802-18.

29. Holtkamp M, Othman J, Buchheim K, Masuhr F, Schielke E, Meierkord H. A "malignant" variant of status epilepticus. Arch Neurol. 2005;62(9):1428-31.

30. Shorvon S, Baulac M, Cross H, Trinka E, Walker M. The drug treatment of status epilepticus in europe: Consensus document from a workshop at the first london colloquium on status epilepticus. Epilepsia. 2008;49(7):1277-85.

31. Jones S, Pahl C, Trinka E, Nashef L. A protocol for the inhospital emergency drug management of convulsive status epilepticus in adults. Pract Neurol. 2014;14(3):194-7.

32. Meierkord H, Boon P, Engelsen B, Gocke K, Shorvon S, Tinuper P, Holtkamp M. European Federation of Neurological S: Efns guideline on the management of status epilepticus in adults. Eur J Neurol. 2010;17(3):348-55.

33. Janz D. Historical vignette: medical treatment of status epilepticus. Epilepsia. 2013;54(Suppl 6):3-10.

34. Neligan A, Shorvon SD. The history of status epilepticus and its treatment. Epilepsia. 2009;50(Suppl 3):56-68.

35. Prasad K, Al Roomi K, Krishnan PR, Sequeira R. Anticonvulsant therapy for status epilepticus. Cochrane Database Syst Rev. 2005;4:CD003723.

36. Prasad K, Krishnan PR, Al Roomi K, Sequeira R. Anticonvulsant therapy for status epilepticus. Br J Clin Pharmacol. 2007;63(6):640-7.

37. Brigo F, Storti M, Del Felice A, Fiaschi A, Bongiovanni LG. Iv valproate in generalized convulsive status epilepticus: A systematic review. Eur J Neurol. 2012;19(9):1180-91.

38. Haynes RB. Of studies, syntheses, synopses, summaries, and systems: the " $5 \mathrm{~s}$ " evolution of information services for evidence-based healthcare decisions. Evid Based Med. 2006;11(6):162-4.

39. Trinka E. Benzodiazepines used primarily for emergency treatment (diazepam, lorazepam, and midazolam). In: Shorvon SD, Perucca E, Engel Jr J, editors. Treatment of epilepsies. 3rd ed. Oxford: Blackwell Publishing; 2009. p. 470-84.

40. Alldredge BK, Gelb AM, Isaacs SM, Corry MD, Allen F, Ulrich S, Gottwald MD, O'Neil N, Neuhaus JM, Segal MR, Lowenstein DH. A comparison of lorazepam, diazepam, and placebo for the treatment of out-of-hospital status epilepticus. N Engl J Med. 2001;345(9):631-7.

41. Leppik IE, Derivan AT, Homan RW, Walker J, Ramsay RE, Patrick B. Double-blind study of lorazepam and diazepam in status epilepticus. J Am Med Assoc. 1983;249:1452-4.

42. Appleton R, Sweeney A, Choonara I, Robson J, Molyneux E. Lorazepam versus diazepam in the acute treatment of epileptic seizures and status epilepticus. Dev Med Child Neurol. 1995;37(8):682-8.

43. Chamberlain JM, Okada P, Holsti M, Mahajan P, Brown KM, Vance C, Gonzalez V, Lichenstein R, Stanley R, Brousseau DC, Grubenhoff $\mathrm{J}$, et al. Lorazepam vs diazepam for pediatric status epilepticus: A randomized clinical trial. JAMA. 2014;311(16):1652-60.

44. Silbergleit R, Durkalski V, Lowenstein D, Conwit R, Pancioli A, Palesch Y, Barsan W, Investigators N. Intramuscular versus intravenous therapy for prehospital status epilepticus. The New England journal of medicine. 2012;366(7):591-600.

45. Prasad M, Krishnan PR, Sequeira R, Al-Roomi K. Anticonvulsant therapy for status epilepticus. Cochrane Database Syst Rev. 2014;9:CD003723.
46. Wermeling DP, Miller JL, Archer SM, Manaligod JM, Rudy AC. Bioavailability and pharmacokinetics of lorazepam after intranasal, intravenous, and intramuscular administration. J Clin Pharmacol. 2001;41(11):1225-31.

47. Anderson M, Tambe P, Sammons H, Mulla H, Cole R, Choonara I. Pharmacokinetics of buccal and intranasal lorazepam in healthy adult volunteers. Eur J Clin Pharmacol. 2012;68(2):155-9.

48. Arya R, Gulati S, Kabra M, Sahu JK, Kalra V. Intranasal versus intravenous lorazepam for control of acute seizures in children: A randomized open-label study. Epilepsia. 2011;52(4):788-93.

49. Cereghino JJ, Cloyd JC, Kuzniecky RI. Rectal diazepam gel for treatment of acute repetitive seizures in adults. Arch Neurol. 2002;59(12):1915-20.

50. Cereghino JJ, Mitchell WG, Murphy J, Kriel RL, Rosenfeld WE, Trevathan E. Treating repetitive seizures with a rectal diazepam formulation: a randomized study. The north american diastat study group. Neurology. 1998;51(5):1274-82.

51. Kriel RL, Cloyd JC, Pellock JM, Mitchell WG, Cereghino JJ, Rosman NP. Rectal diazepam gel for treatment of acute repetitive seizures. The north american diastat study group. Pediatr Neurol. 1999;20(4):282-8.

52. Dreifuss FE, Rosman NP, Cloyd JC, Pellock JM, Kuzniecky RI, Lo WD, Matsuo F, Sharp GB, Conry JA, Bergen DC, Bell WE. A comparison of rectal diazepam gel and placebo for acute repetitive seizures. N Engl J Med. 1998;338(26):1869-75.

53. Remy C, Jourdil N, Villemain D, Favel P, Genton P. Intrarectal diazepam in epileptic adults. Epilepsia. 1992;33(2):353-8.

54. Congdon PJ, Forysthe WI. Intravenous clonazepam in the treatment of status epilepticus in children. Epilepsia. 1980;21:97-102.

55. Singh AN, Le Morvan P. Treatment of status epilepticus with intravenous clonazepam. Prog Neuropsychopharmacol Biol Psychiatry. 1982;6(4-6):539-42.

56. Navarro V, Dagron C, Demeret S, An K, Lamhaut L, Bolgert F, Baulac M, Carli P. A prehospital randomized trial in convulsive status epilepticus. Epilepsia. 2011;52(Suppl 8):48-9.

57. Patsalos PN, Bell DM, Richards G, Sander JWAS, Oxley JR, Dhillion S, Cromarty J. Pharmacokinetic evaluation of intravenous and intramuscular midazolam in patients with epilepsy. Epilepsia. 1991;32(suppl. 1):29.

58. Gathwala G, Goel M, Singh J, Mittal K. Intravenous diazepam, midazolam and lorazepam in acute seizure control. Indian $\mathrm{J}$ Pediatr. 2012;79(3):327-32.

59. Lahat E, Goldman M, Barr J, Bistritzer T, Berkovitch M. Comparison of intranasal midazolam with intravenous diazepam for treating febrile seizures in children: prospective randomised study. BMJ. 2000;321(7253):83-6.

60. Mahmoudian T, Zadeh MM. Comparison of intranasal midazolam with intravenous diazepam for treating acute seizures in children. Epilepsy Behav. 2004;5(2):253-5.

61. Thakker A, Shanbag P. A randomized controlled trial of intranasal-midazolam versus intravenous-diazepam for acute childhood seizures. J Neurol. 2013;260(2):470-4.

62. Fisgin T, Gurer Y, Tezic T, Senbil N, Zorlu P, Okuyaz C, Akgun D. Effects of intranasal midazolam and rectal diazepam on acute convulsions in children: Prospective randomized study. J Child Neurol. 2002;17(2):123-6.

63. McIntyre J, Robertson S, Norris E, Appleton R, Whitehouse WP, Phillips B, Martland T, Berry K, Collier J, Smith S, Choonara I. Safety and efficacy of buccal midazolam versus rectal diazepam for emergency treatment of seizures in children: a randomised controlled trial. Lancet. 2005;366(9481):205-10.

64. Talukdar B, Chakrabarty B. Efficacy of buccal midazolam compared to intravenous diazepam in controlling convulsions in 
children: a randomized controlled trial. Brain Dev. 2009;31(10):744-9.

65. Scott RC, Besag FM, Neville BG. Buccal midazolam and rectal diazepam for treatment of prolonged seizures in childhood and adolescence: a randomised trial. Lancet. 1999;353(9153):623-6.

66. Mpimbaza A, Ndeezi G, Staedke S, Rosenthal PJ, Byarugaba J. Comparison of buccal midazolam with rectal diazepam in the treatment of prolonged seizures in ugandan children: a randomized clinical trial. Pediatrics. 2008;121(1):e58-64.

67. Shah I, Deshmukh CT. Intramuscular midazolam vs intravenous diazepam for acute seizures. Indian J Pediatr. 2005;72(8):667-70.

68. Carter C. Use of parenteral diphenylhydantoin (dilantin) sodium in control of status epilepticus. Arch Neurol Psychiatry. 1958;79:136-7.

69. Wilder BJ, Ramsay RE, Willmore LJ, Feussner GF, Perchalski RJ, Shumate JB. Efficacy of intravenous phenytoin in the treatment of status epilepticus: kinetics of central nervous system penetration. Ann Neurol. 1977:1;511-8.

70. Feddersen B, Trinka E. Status epilepticus. Nervenarzt. 2012;83(2):187-94.

71. Cranford RE, Leppik IE, Patrick B, Anderson CB, Kostick B. Intravenous phenytoin in acute treatment of seizures. Neurology. 1979;29(11):1474-9.

72. Leppik IE, Patrick BK, Cranford RE. Treatment of acute seizures and status epilepticus with intravenous phenytoin. In: Escueta AVD, Wasterlain CG, Treiman DM, Porter RJ, editors. Status epileptics: mechaisms of brain damage and treatment. Advances in neurology, vol. 34. New York: Raven Press; 1983. pp. 447-52.

73. Burneo JG, Anandan JV, Barkley GL. A prospective study of the incidence of the purple glove syndrome. Epilepsia. 2001;42(9):1156-9.

74. O'Brien TJ, Cascino GD, So EL, Hanna DR. Incidence and clinical consequence of the purple glove syndrome in patients receiving intravenous phenytoin. Neurology. 1998;51(4):1034-9.

75. Appleton RE, Gill A. Adverse events associated with intravenous phenytoin in children: a prospective study. Seizure. 2003;12(6):369-72.

76. Chhabra P, Gupta N, Kaushik A. Compartment syndrome as a spectrum of purple glove syndrome following intravenous phenytoin administration in a young male: A case report and review of literature. Neurology India. 2013;61(4):419-20.

77. McWilliam PKA. Intravenous phenytoin sodium in continuous convulsions in children. Lancet. 1958;2:1147-1149.

78. Leppik IE, Patrick BK, Cranford RE. Treatment of acute seizures and status epilepticus with intravenous phenytoin. Adv Neurol. 1983;34:447-51.

79. Wallis W, Kutt H, McDowell F. Intravenous diphenyl hydantoin treatment of acute repetitive seizures. Neurology. 1968;18:513-25.

80. von Albeert HH. A new phenytoin infusion concentrate for status epilepticus. In: Escueta AVD, Wasterlain CG, Treiman DM, Porter RJ, editors. Status epilepticus: mechanisms of brain damage and treatment. Advances in neruology, vol. 34. New York: Raven Press; 1983. pp. 453-456.

81. Treiman DM, Meyers PD, Walton NY, Collins JF, Colling C, Rowan AJ, Handforth A, Faught E, Calabrese VP, Uthman BM, Ramsay RE et al. A comparison of four treatments for generalized convulsive status epilepticus. Veterans affairs status epilepticus cooperative study group. $\mathrm{N}$ Engl J Med. 1998;339(12):792-8.

82. Misra UK, Kalita J, Patel R. Sodium valproate vs phenytoin in status epilepticus: A pilot study. Neurology. 2006;67(2):340-2.
83. Agarwal P, Kumar N, Chandra R, Gupta G, Antony AR, Garg N. Randomized study of intravenous valproate and phenytoin in status epilepticus. Seizure. 2007;16(6):527-32.

84. Gilad R, Izkovitz N, Dabby R, Rapoport A, Sadeh M, Weller B, Lampl Y. Treatment of status epilepticus and acute repetitive seizures with i.V. Valproic acid vs phenytoin. Acta Neurol Scand. 2008;118(5):296-300.

85. Trinka E. What is the relative value of the standard anticonvulsants: phenytoin and fosphenytoin, phenobarbital, valproate, and levetiracetam? Epilepsia. 2009;50(Suppl 12):40-3.

86. Ramsay RE, Wilder BJ, Uthman BM, Garnett WR, Pellock JM, Barkley GL, Leppik IE, Knapp LE. Intramuscular fosphenytoin (cerebyx) in patients requiring a loading dose of phenytoin. Epilepsy Res. 1997;28(3):181-7.

87. Wilder BJ, Campbell K, Ramsay RE, Garnett WR, Pellock JM, Henkin SA, Kugler AR. Safety and tolerance of multiple doses of intramuscular fosphenytoin substituted for oral phenytoin in epilepsy or neurosurgery. Arch Neurol. 1996;53(8):764-8.

88. Lowenstein DH, Alldredge BK. Status epilepticus. N Engl J Med. 1998;338(14):970-6.

89. Perucca E. Pharmacological and therapeutic properties of valproate: a summary after 35 years of clinical experience. CNS Drugs. 2002;16(10):695-714.

90. Zaccara G, Franciotta D, Perucca E. Idiosyncratic adverse reactions to antiepileptic drugs. Epilepsia. 2007;48(7):1223-44.

91. Genton P, Semah F, Trinka E. Valproic acid in epilepsy: pregnancy-related issues. Drug Saf. 2006;29(1):1-21.

92. Gerstner T, Busing D, Bell N, Longin E, Kasper JM, Klostermann W, Hebing B, Hanefeld F, Eckel U, Hoffmann R, Bettendorf $\mathrm{U}$, et al. Valproic acid-induced pancreatitis: 16 new cases and a review of the literature. $\mathrm{J}$ Gastroenterol. 2007;42(1):39-48.

93. Konig SA, Schenk M, Sick C, Holm E, Heubner C, Weiss A, Konig I, Hehlmann R. Fatal liver failure associated with valproate therapy in a patient with friedreich's disease: review of valproate hepatotoxicity in adults. Epilepsia. 1999;40(7):1036-40.

94. Konig SA, Siemes H, Blaker F, Boenigk E, Gross-Selbeck G, Hanefeld F, Haas N, Kohler B, Koelfen W, Korinthenberg R. Severe hepatotoxicity during valproate therapy: an update and report of eight new fatalities. Epilepsia. 1994;35(5):1005-15.

95. Bialer M, Hussein Z, Dubrovsky J, Raz I, Abramsky O. Pharmacokinetics of valproic acid obtained after administration of three oral formulations to humans. Isr $\mathrm{J}$ Med Sci. 1984;20(1):46-9.

96. Hussein Z, Mukherjee D, Lamm J, Cavanaugh JH, Granneman GR. Pharmacokinetics of valproate after multiple-dose oral and intravenous infusion administration: gastrointestinal-related diurnal variation. J Clin Pharmacol. 1994;34(7):754-9.

97. Hussein Z, Patterson KJ, Lamm JE, Cavanaugh JH, Granneman GR. Effect of infusion duration on valproate pharmacokinetics. Biopharm Drug Dispos. 1993;14(5):389-99.

98. Honack D, Loscher W. Intravenous valproate: onset and duration of anticonvulsant activity against a series of electroconvulsions in comparison with diazepam and phenytoin. Epilepsy Res. 1992;13(3):215-21.

99. Walton NY, Treiman DM. Valproic acid treatment of experimental status epilepticus. Epilepsy Res. 1992;12(3):199-205.

100. Trinka E, Hofler J, Zerbs A, Brigo F. Efficacy and safety of intravenous valproate for status epilepticus: a systematic review. CNS drugs. 2014;28(7):623-39.

101. Limdi NA, Faught E. The safety of rapid valproic acid infusion. Epilepsia. 2000;41(10):1342-5.

102. Limdi NA, Knowlton RK, Cofield SS, Ver Hoef LW, Paige AL, Dutta S, Faught E. Safety of rapid intravenous loading of valproate. Epilepsia. 2007;48(3):478-83. 
103. Limdi NA, Shimpi AV, Faught E, Gomez CR, Burneo JG. Efficacy of rapid iv administration of valproic acid for status epilepticus. Neurology. 2005;64(2):353-5.

104. Kramer G, Bergmann A, Deshpande LS, Kînig S, Kurth C, Kurlemann G, Loscher W, Luef G, Meierkord H, Noachtar S, Pohlmann-Eden B, et al. Current place of intravenous valproic acid in the treatment of generalized tonic-clonic status epilepticus. Aktuelle Neurol. 2005;32(5):263-74.

105. Sinha S, Naritoku DK. Intravenous valproate is well tolerated in unstable patients with status epilepticus. Neurology. 2000;55(5):722-4.

106. Embacher N, Karner E, Wanschitz J, Beer R, Trinka E. Acute encephalopathy after intravenous administration of valproate in non-convulsive status epilepticus. Eur J Neurol. 2006;13(10):e5-6.

107. Trinka E, Dobesberger J, Brîssner G, Walser G, Embacher N, Unterberger I, Pittschieler S, Luef G, Haberlandt E, Auckenthaler A, Schmutzhard E, et al. Treatment of status epilepticus. A retrospective analysis of 248 patients. Epilepsia. 2006;47(s3): 16 .

108. Gidal BE, Baltes E, Otoul C, Perucca E. Effect of levetiracetam on the pharmacokinetics of adjunctive antiepileptic drugs: A pooled analysis of data from randomized clinical trials. Epilepsy Res. 2005;64(1-2):1-11.

109. Otoul C, Arrigo C, van Rijckevorsel K, French JA. Meta-analysis and indirect comparisons of levetiracetam with other second-generation antiepileptic drugs in partial epilepsy. Clin Neuropharmacol. 2005;28(2):72-8.

110. Patsalos PN. Clinical pharmacokinetics of levetiracetam. Clin Pharmacokinet. 2004;43(11):707-24.

111. Mazarati AM, Baldwin R, Klitgaard H, Matagne A, Wasterlain CG. Anticonvulsant effects of levetiracetam and levetiracetamdiazepam combinations in experimental status epilepticus. Epilepsy Res. 2004;58(2-3):167-74.

112. Trinka $E$. What is the evidence to use new intravenous AEDs in status epilepticus? Epilepsia. 2011;52(Suppl 8):35-8.

113. Trinka E, Dobesberger J. New treatment options in status epilepticus: a critical review on levetiracetam. Ther Adv Neurol Dis. 2009;2(2):79-91.

114. Zelano J, Kumlien E. Levetiracetam as alternative stage two antiepileptic drug in status epilepticus: a systematic review. Seizure. 2012;21(4):233-6.

115. Yasiry Z, Shorvon SD. The relative effectiveness of five antiepileptic drugs in treatment of benzodiazepine-resistant convulsive status epilepticus: a meta-analysis of published studies. Seizure. 2014;23(3):167-74.

116. Misra UK, Kalita J, Maurya PK. Levetiracetam versus lorazepam in status epilepticus: a randomized, open labeled pilot study. J Neurol. 2012;259(4):645-8.

117. Shaner DM, McCurdy SA, Herring MO, Gabor AJ. Treatment of status epilepticus: a prospective comparison of diazepam and phenytoin versus phenobarbital and optional phenytoin. Neurology. 1988;38:202-7.

118. Mayer SA, Claassen J, Lokin J, Mendelsohn F, Dennis LJ, Fitzsimmons BF. Refractory status epilepticus: frequency, risk factors, and impact on outcome. Arch Neurol. 2002;59(2): 205-10.

119. Holtkamp M, Othman J, Buchheim K, Meierkord H. Predictors and prognosis of refractory status epilepticus treated in a neurological intensive care unit. J Neurol Neurosurg Psychiatry. 2005;76(4):534-9.

120. Kalviainen R, Eriksson K, Parviainen I. Refractory generalised convulsive status epilepticus : A guide to treatment. CNS Drugs. 2005;19(9):759-68.
121. Rossetti AO. Which anesthetic should be used in the treatment of refractory status epilepticus? Epilepsia. 2007;48(Suppl 8):52-5.

122. Holtkamp M. The anaesthetic and intensive care of status epilepticus. Curr Opin Neurol. 2007;20(2):188-93.

123. Claassen J, Hirsch LJ, Emerson RG, Mayer SA. Treatment of refractory status epilepticus with pentobarbital, propofol, or midazolam: a systematic review. Epilepsia. 2002;43(2):146-53.

124. Ferlisi M, Shorvon S. The outcome of therapies in refractory and super-refractory convulsive status epilepticus and recommendations for therapy. Brain. 2012;135(Pt 8):2314-28.

125. Niermeijer JM, Uiterwaal CS, Van Donselaar CA. Propofol in status epilepticus: Little evidence, many dangers? J Neurol. 2003;250(10):1237-40.

126. Sutter R, Marsch S, Fuhr P, Kaplan PW, Ruegg S. Anesthetic drugs in status epilepticus: risk or rescue? A 6-year cohort study. Neurology. 2014;82(8):656-64.

127. Singhi S, Murthy A, Singhi P, Jayashree M. Continuous midazolam versus diazepam infusion for refractory convulsive status epilepticus. J Child Neurol. 2002;17(2):106-10.

128. Fernandez A, Lantigua H, Lesch C, Shao B, Foreman B, Schmidt JM, Hirsch LJ, Mayer SA, Claassen J. High-dose midazolam infusion for refractory status epilepticus. Neurology. 2014;82(4):359-65.

129. Zhan RZ, Qi S, Wu C, Fujihara H, Taga K, Shimoji K. Intravenous anesthetics differentially reduce neurotransmission damage caused by oxygen-glucose deprivation in rat hippocampal slices in correlation with n-methyl-d-aspartate receptor inhibition. Crit Care Med. 2001;29(4):808-13.

130. Marik PE. Propofol: therapeutic indications and side-effects. Current Pharm Des. 2004;10(29):3639-49.

131. Marik PE. Propofol: an immunomodulating agent. Pharmacotherapy. 2005;25(5 Pt 2):28S-33S.

132. Zarovnaya EL, Jobst BC, Harris BT. Propofol-associated fatal myocardial failure and rhabdomyolysis in an adult with status epilepticus. Epilepsia. 2007;48(5):1002-6.

133. Mayette M, Gonda J, Hsu JL, Mihm FG. Propofol infusion syndrome resuscitation with extracorporeal life support: a case report and review of the literature. Ann Intensiv Care. 2013;3(1):32.

134. Mirrakhimov AE, Voore P, Halytskyy O, Khan M, Ali AM. Propofol infusion syndrome in adults: a clinical update. Crit Care Res Pract. 2015. doi:10.1155/2015/260385.

135. Rossetti AO, Milligan TA, Vulliemoz S, Michaelides C, Bertschi M, Lee JW. A randomized trial for the treatment of refractory status epilepticus. Neurocrit Care. 2011;14(1):4-10.

136. Prabhakar H, Bindra A, Singh GP, Kalaivani M. Propofol versus thiopental sodium for the treatment of refractory status epilepticus. Cochrane Database Syst Rev. 2012;8:CD009202.

137. Lowenstein DH, Aminoff MJ, Simon RP. Barbiturate anesthesia in the treatment of status epilepticus. Clinical experience of 14 patients. Neurology. 1988;38:395-400.

138. Melamed R, Bar-Yosef S, Shakhar G, Shakhar K, Ben-Eliyahu $\mathrm{S}$. Suppression of natural killer cell activity and promotion of tumor metastasis by ketamine, thiopental, and halothane, but not by propofol: Mediating mechanisms and prophylactic measures. Anesth Analg. 2003;97(5):1331-9.

139. Stover JF, Stocker R. Barbiturate coma may promote reversible bone marrow suppression in patients with severe isolated traumatic brain injury. Eur J Clin Pharmacol. 1998;54(7):529-34.

140. Tian J, Chau C, Hales TG, Kaufman DL. Gaba(a) receptors mediate inhibition of $\mathrm{t}$ cell responses. $\mathrm{J}$ Neuroimmunol. 1999;96(1):21-8.

141. Kofke WA, Young RSK, Davis P, Woelfel SK, Gray L, Johnson D, Gelb A, Meeke R, Warner DS, Pearson KS, Gibson JR et al. 
Isoflurane for refractory status epilepticus: a clinical series. Anesthesiology. 1989;71:653-9.

142. Mirsattari SM, Sharpe MD, Young GB. Treatment of refractory status epilepticus with inhalational anesthetic agents isoflurane and desflurane. Arch Neurol. 2004;61(8):1254-9.

143. Rossetti AO. Novel anesthetics and other treatment strategies for refractory status epilepticus. Epilepsia. 2009;50(Suppl 12):51-3.

144. van den Heuvel I, Wurmb TE, Bottiger BW, Bernhard M. Pros and cons of etomidate-more discussion than evidence? Curr Opin Anaesthesiol. 2013;26(4):404-8.

145. Yeoman P, Hutchinson A, Byrne A, Smith J, Durham S. Etomidate infusions for the control of refractory status epilepticus. Intensiv Care Med. 1989;15:255-9.

146. Borris DJ, Bertram EH, Kapur J. Ketamine controls prolonged status epilepticus. Epilepsy Res. 2000;42(2-3):117-22.

147. Kapur J, Coulter DA. Experimental status epilepticus alters gamma-aminobutyric acid type a receptor function in cal pyramidal neurons. Ann Neurol. 1995;38(6):893-900.

148. Mazarati AM, Wasterlain CG. $N$-methyl-D-asparate receptor antagonists abolish the maintenance phase of self-sustaining status epilepticus in rat. Neurosci Lett. 1999;265(3):187-90.

149. Synowiec AS, Singh DS, Yenugadhati V, Valeriano JP, Schramke CJ, Kelly KM. Ketamine use in the treatment of refractory status epilepticus. Epilepsy Res. 2013;105(1-2):183-8.

150. Gaspard N, Foreman B, Judd LM, Brenton JN, Nathan BR, McCoy BM, Al-Otaibi A, Kilbride R, Fernandez IS, Mendoza L, Samuel S, et al. Intravenous ketamine for the treatment of refractory status epilepticus: a retrospective multicenter study. Epilepsia. 2013;54(8):1498-503.

151. Hsieh CY, Sung PS, Tsai JJ, Huang CW. Terminating prolonged refractory status epilepticus using ketamine. Clin Neuropharmacol. 2010;33(3):165-7.

152. Kofke WA, Bloom MJ, Van Cott A, Brenner RP. Electrographic tachyphylaxis to etomidate and ketamine used for refractory status epilepticus controlled with isoflurane. J Neurosurg Anesthesiol. 1997;9(3):269-72.

153. Kramer AH. Early ketamine to treat refractory status epilepticus. Neurocrit Care. 2012;16(2):299-305.

154. Pruss H, Holtkamp M. Ketamine successfully terminates malignant status epilepticus. Epilepsy Res. 2008;82(2-3):219-22.

155. Robakis TK, Hirsch LJ. Literature review, case report, and expert discussion of prolonged refractory status epilepticus. Neurocrit Care. 2006;4(1):35-46.

156. Sheth RD, Gidal BE. Refractory status epilepticus: response to ketamine. Neurology. 1998;51(6):1765-6.

157. Ubogu EE, Sagar SM, Lerner AJ, Maddux BN, Suarez JI, Werz MA. Ketamine for refractory status epilepticus: a case of possible ketamine-induced neurotoxicity. Epilepsy Behav. 2003;4(1):70-5.

158. Yeh PS, Shen HN, Chen TY. Oral ketamine controlled refractory nonconvulsive status epilepticus in an elderly patient. Seizure. 2011;20(9):723-6.

159. Zeiler FA, Kaufmann AM, Gillman LM, West M, Silvaggio J. Ketamine for medically refractory status epilepticus after elective aneurysm clipping. Neurocrit Care. 2013;19(1):119-24.

160. Walker MC, Howard RS, Smith SJ, Miller DH, Shorvon SD, Hirsch NP. Diagnosis and treatment of status epilepticus on a neurological intensive care unit. QJM. 1996;89(12):913-20.

161. Duley L, Henderson-Smart DJ, Chou D. Magnesium sulphate versus phenytoin for eclampsia. Cochrane Database Syst Rev. 2010;10:CD000128.

162. Storchheim F. Status epilepticus treated by magnesium sulphate, injected intravenously. J Am Med Assoc. 1933;101:1313-4.
163. Visser NA, Braun KP, Leijten FS, van Nieuwenhuizen O, Wokke JH, van den Bergh WM. Magnesium treatment for patients with refractory status epilepticus due to polg1-mutations. J Neurol. 2011;258(2):218-22.

164. Shank RP, Gardocki JF, Streeter AJ, Maryanoff BE. An overview of the preclinical aspects of topiramate: pharmacology, pharmacokinetics, and mechanism of action. Epilepsia. 2000;41(Suppl 1):S3-9.

165. Hottinger A, Sutter R, Marsch S, Ruegg S. Topiramate as an adjunctive treatment in patients with refractory status epilepticus: an observational cohort study. CNS drugs. 2012;26(9):761-72.

166. Vezzani A. Epilepsy and inflammation in the brain: overview and pathophysiology. Epilepsy Curr. 2014;14(1 Suppl):3-7.

167. Vezzani A, Aronica E, Mazarati A, Pittman QJ. Epilepsy and brain inflammation. Exp Neurol. 2013;244:11-21.

168. Vezzani A, Balosso S, Aronica E, Ravizza T. Basic mechanisms of status epilepticus due to infection and inflammation. Epilepsia. 2009;50(Suppl 12):56-7.

169. Chung S, Ben-Menachem E, Sperling MR, Rosenfeld W, Fountain NB, Benbadis S, Hebert D, Isojarvi J, Doty P. Examining the clinical utility of lacosamide: pooled analyses of three phase ii/iii clinical trials. CNS Drugs. 2010;24(12):1041-54.

170. Ben-Menachem E, Biton V, Jatuzis D, Abou-Khalil B, Doty P, Rudd GD. Efficacy and safety of oral lacosamide as adjunctive therapy in adults with partial-onset seizures. Epilepsia. 2007;48(7):1308-17.

171. Ben-Menachem E. Lacosamide: an investigational drug for adjunctive treatment of partial-onset seizures. Drugs Today. 2008;44(1):35-40.

172. Krauss G, Ben-Menachem E, Mameniskiene R, Vaiciene-Magistris N, Brock M, Whitesides JG, Johnson ME, Group SPS. Intravenous lacosamide as short-term replacement for oral lacosamide in partial-onset seizures. Epilepsia. 2010;51(6):951-7.

173. Biton V, Rosenfeld WE, Whitesides J, Fountain NB, Vaiciene $\mathrm{N}$, Rudd GD. Intravenous lacosamide as replacement for oral lacosamide in patients with partial-onset seizures. Epilepsia. 2008;49(3):418-24.

174. Wasterlain CG, Stohr T, Matagne A. The acute and chronic effects of the novel anticonvulsant lacosamide in an experimental model of status epilepticus. Epilepsy Res. 2011;94(1-2):10-7.

175. Kellinghaus C, Berning S, Besselmann M. Intravenous lacosamide as successful treatment for nonconvulsive status epilepticus after failure of first-line therapy. Epilepsy Behav. 2009;14(2):429-31.

176. Hofler J, Trinka E. Lacosamide as a new treatment option in status epilepticus. Epilepsia. 2013;54(3):393-404.

177. Kellinghaus C, Berning S, Immisch I, Larch J, Rosenow F, Rossetti AO, Tilz C, Trinka E. Intravenous lacosamide for treatment of status epilepticus. Acta Neurol Scand. 2011;123(2):137-41.

178. Hofler J, Unterberger I, Dobesberger J, Kuchukhidze G, Walser $\mathrm{G}$, Trinka E. Intravenous lacosamide in status epilepticus and seizure clusters. Epilepsia. 2011;52(10):e148-52.

179. Kellinghaus C. Lacosamide as treatment for partial epilepsy: mechanisms of action, pharmacology, effects, and safety. Ther Clinical Risk Manag. 2009;5:757-66.

180. Krause LU, Brodowski KO, Kellinghaus C. Atrioventricular block following lacosamide intoxication. Epilepsy Behav. 2011;20(4):725-7.

181. Kubova H, Rejchrtova J, Redkozubova O, Mares P. Outcome of status epilepticus in immature rats varies according to the paraldehyde treatment. Epilepsia. 2005;46(Suppl 5)38-42. 
182. Rowland AG, Gill AM, Stewart AB, Appleton RE, Al Kharusi A, Cramp C, Yeung LK. Review of the efficacy of rectal paraldehyde in the management of acute and prolonged tonic-clonic convulsions. Arch Dis Child. 2009;94(9):720-3.

183. Ahmad S, Ellis JC, Kamwendo H, Molyneux E. Efficacy and safety of intranasal lorazepam versus intramuscular paraldehyde for protracted convulsions in children: An open randomised trial. Lancet. 2006;367(9522):1591-7.

184. Bernhard CG, Bohm E, Hojeberg S. A new treatment of status epilepticus; intravenous injections of a local anesthetic (lidocaine). AMA Archiv Neurol Psychiatry. 1955;74(2):208-14.

185. Hattori H, Yamano T, Hayashi K, Osawa M, Kondo K, Aihara M, Haginoya K, Hamano S, Izumi T, Kaneko K, Kato I, et al. Effectiveness of lidocaine infusion for status epilepticus in childhood: a retrospective multi-institutional study in japan. Brain Dev. 2008;30(8):504-12.

186. Kobayashi O, Iwasaki Y, Yamanouchi H, Sugai K. A case of refractory status epilepticus associated with aberrant intracranial shunt tube: efficacy of lidocaine in the determination of the epileptic focus. No To Hattatsu. 1994;26(4):329-34.

187. Yildiz B, Citak A, Ucsel R, Karabocuoglu M, Aydinli N, Uzel N. Lidocaine treatment in pediatric convulsive status epilepticus. Pediatr Int. 2008;50(1):35-9.

188. Walker IA, Slovis CM. Lidocaine in the treatment of status epilepticus. Acad Emerg Med. 1997;4(9):918-22.

189. Hamano S, Sugiyama N, Yamashita S, Tanaka M, Hayakawa M, Minamitani M, Yoshinari S, Eto Y. Intravenous lidocaine for status epilepticus during childhood. Dev Med Child Neurol. 2006;48(3):220-2.

190. Sugiyama N, Hamano S, Mochizuki M, Tanaka M, Eto Y. Efficacy of lidocaine on seizures by intravenous and intravenous-drip infusion. No To Hattatsu. 2004;36(6):451-4.

191. Garcia Garcia MJ, Lopez-Herce Cid J, Martinez Bermejo A, Perdikidi Olivieri L, Rubio de la Iglesia F, Hernandez Gonzalez J. Teatment of refractory status convulsivus with chlormethiazole. An Esp Pediatr. 1988;29(4):324-6.

192. Harvey PK, Higenbottam TW, Loh L. Chlormethiazole in treatment of status epilepticus. Br Med J. 1975;2(5971):603-5.

193. Martinovic Z, Jovic N. Chlormethiazole in the treatment of complex partial epileptic status in childhood. Srp Arh Celok Lek. 1991;119(1-2):53-7.

194. Miller P, Kovar I. Chlormethiazole in the treatment of neonatal status epilepticus. Postgrad Med J. 1983;59(698):801-2.

195. Miller P, Kovar I. Chlormethiazole in the treatment of neonatal status epilepticus. Postgrad Med J. 1983;59:801-2.

196. Loscher W, Honack D. Intravenous carbamazepine: comparison of different parenteral formulations in a mouse model of convulsive status epilepticus. Epilepsia. 1997;38(1):106-13.

197. Loscher W, Honack D, Richter A, Schulz HU, Schurer M, Dusing R, Brewster ME. New injectable aqueous carbamazepine solution through complexing with 2-hydroxypropyl-beta-cyclodextrin: tolerability and pharmacokinetics after intravenous injection in comparison to a glycofurol-based formulation. Epilepsia. 1995;36(3):255-61.

198. Kelmann RG, Kuminek G, Teixeira HF, Koester LS. Preliminary study on the development of nanoemulsions for carbamazepine intravenous delivery: an investigation of drug polymorphic transition. Drug Dev Ind Pharm. 2008;34(1):53-8.

199. Kelmann RG, Kuminek G, Teixeira HF, Koester LS. Carbamazepine parenteral nanoemulsions prepared by spontaneous emulsification process. Int J Pharm. 2007;342(1-2):231-9.

200. Ahmed GF, Brundage RC, Marino SE, Cloyd JC, Leppik IE, Pennell PB, Ramsay RE, Birnbaum AK. Population pharmacokinetics of unbound and total drug concentrations following intravenously administered carbamazepine in elderly and younger adult patients with epilepsy. J Clin Pharmacol. 2013;53(3):276-84

201. Franco V, Iudice A, Grillo E, Citraro R, De Sarro G, Russo E. Perspective on the use of perampanel and intravenous carbamazepine for generalized seizures. Exp Opin Pharmacother. 2014;15(5):637-44.

202. Patel V, Cordato DJ, Malkan A, Beran RG. Rectal carbamazepine as effective long-acting treatment after cluster seizures and status epilepticus. Epilepsy Behav. 2014;31:31-33.

203. Rossetti AO, Logroscino G, Bromfield EB. A clinical score for prognosis of status epilepticus in adults. Neurology. 2006;66(11):1736-8.

204. Rossetti AO, Novy J, Ruffieux C, Olivier P, Foletti GB, Hayoz D, Burnand B, Logroscino G. Management and prognosis of status epilepticus according to hospital setting: a prospective study. Swiss Med Wkly. 2009;139(49-50):719-23.

205. Sutter R, Kaplan PW, Marsch S, Hammel EM, Ruegg S, Ziai WC. Early predictors of refractory status epilepticus: an international two-center study. Eur J Neurol. 2015;22(1):79-85.

206. Towne AR, Pellock JM, Ko D, DeLorenzo RJ. Determinants of mortality in status epilepticus. Epilepsia. 1994;35(1):27-34.

207. Rossetti AO, Alvarez V, Januel JM, Burnand B. Treatment deviating from guidelines does not influence status epilepticus prognosis. J Neurol. 2013;260(2):421-8.

208. Aranda A, Foucart G, Ducasse JL, Grolleau S, McGonigal A, Valton L. Generalized convulsive status epilepticus management in adults: a cohort study with evaluation of professional practice. Epilepsia. 2010;51(10):2159-67.

209. Scholtes FB, Renier WO, Meinardi H. Generalized convulsive status epilepticus: Pathophysiology and treatment. Pharm World Sci. 1993;15(1):17-28.

210. Vignatelli L, Rinaldi R, Baldin E, Tinuper P, Michelucci R, Galeotti M, de Carolis P, D'Alessandro R. Impact of treatment on the short-term prognosis of status epilepticus in two population-based cohorts. J Neurol. 2008;255(2):197-204.

211. Silbergleit R, Lowenstein D, Durkalski V, Conwit R, Investigators N. Lessons from the rampart study - and which is the best route of administration of benzodiazepines in status epilepticus. Epilepsia. 2013;54(Suppl 6)74-7.

212. Silbergleit R, Lowenstein D, Durkalski V, Conwit R, Neurological Emergency Treatment Trials I. Rampart (rapid anticonvulsant medication prior to arrival trial): a double-blind randomized clinical trial of the efficacy of intramuscular midazolam versus intravenous lorazepam in the prehospital treatment of status epilepticus by paramedics. Epilepsia. 2011;52(Suppl $8): 45-7$.

213. Mayer SA, Claassen J, Lokin J, Mendelsohn F, Dennis LJ, Fitzsimmons BF. Refractory status epilepticus: frequency, risk factors, and impact on outcome. Arch Neurol. 2002;59(2):205-10.

214. Novy J, Logroscino G, Rossetti AO. Refractory status epilepticus: a prospective observational study. Epilepsia. 2010;51(2):251-6.

215. Kellinghaus C, Berning S, Stogbauer F. Intravenous lacosamide or phenytoin for treatment of refractory status epilepticus. Acta Neurol Scand. 2014;129(5):294-9.

216. Bleck T, Cock H, Chamberlain J, Cloyd J, Connor J, Elm J, Fountain N, Jones E, Lowenstein D, Shinnar S, Silbergleit R, et al. The established status epilepticus trial 2013. Epilepsia. 2013;54(Suppl 6):89-92.

217. Chamberlain JM, Altieri MA, Futterman C, Young GM, Ochsenschlager DW, Waisman Y. A prospective, randomized study comparing intramuscular midazolam with intravenous diazepam for the treatment of seizures in children. Pediatr Emerg Care. 1997;13(2):92-4 
218. Chen WB, Gao R, Su YY, Zhao JW, Zhang YZ, Wang L, Ren Y, Fan CQ. Valproate versus diazepam for generalized convulsive status epilepticus: a pilot study. Eur J Neurol. 2011;18(12):1391-6.

219. Malamiri RA, Ghaempanah M, Khosroshahi N, Nikkhah A, Bavarian B, Ashrafi MR. Efficacy and safety of intravenous sodium valproate versus phenobarbital in controlling convulsive status epilepticus and acute prolonged convulsive seizures in children: a randomised trial. Eur J Paediatr Neurol. 2012;16(5):536-41.
220. Mehta V, Singhi P, Singhi S. Intravenous sodium valproate versus diazepam infusion for the control of refractory status epilepticus in children: a randomized controlled trial. J Child Neurol. 2007;22(10):1191-7.

221. McCormick EM, Lieh-Lai M, Knazik S, Nigro M. A prospective comparison of midazolam ans lorazepam in the initial treatment of status epilepticus in the pediatric patient. Epilepsia. 1999;40(s7):160. 